OPEN ACCESS

Edited by:

Yogen Singh,

Cambridge University Hospitals NHS Foundation Trust, United Kingdom

Reviewed by:

Anup C. Katheria,

Sharp Mary Birch Hospital for Women \& Newborns, United States Shazia Bhombal,

Stanford University, United States

*Correspondence:

Mihaela Roxana Popescu roxana.popescu@umfcd.ro

Ana-Maria Zagrean ana-maria.zagrean@umfcd.ro

Specialty section:

This article was submitted to Neonatology,

a section of the journal

Frontiers in Pediatrics

Received: 21 November 2019 Accepted: 12 February 2020

Published: 26 February 2020

Citation:

Popescu MR, Panaitescu AM Pavel B, Zagrean L, Peltecu G and Zagrean A-M (2020) Getting an Early

Start in Understanding Perinatal Asphyxia Impact on the Cardiovascular System. Front. Pediatr. 8:68 doi: 10.3389/fped.2020.00068

\section{Getting an Early Start in Understanding Perinatal Asphyxia Impact on the Cardiovascular System}

\author{
Mihaela Roxana Popescu ${ }^{1 *}$, Anca Maria Panaitescu ${ }^{2}$, Bogdan Pavel ${ }^{3,4}$, Leon Zagrean ${ }^{3}$, \\ Gheorghe Peltecu ${ }^{2}$ and Ana-Maria Zagrean ${ }^{3 *}$
}

${ }^{1}$ Cardiology Department, Elias University Hospital, "Carol Davila" University of Medicine and Pharmacy, Bucharest, Romania, ${ }^{2}$ Department of Obstetrics and Gynecology, Filantropia Clinical Hospital, "Carol Davila" University of Medicine and Pharmacy, Bucharest, Romania, ${ }^{3}$ Division of Physiology and Neuroscience, Department of Functional Sciences, "Carol Davila" University of Medicine and Pharmacy, Bucharest, Romania, ${ }^{4}$ Intensive Care Department, Clinical Emergency Hospital of Plastic Surgery and Burns, Bucharest, Romania

Perinatal asphyxia (PA) is a burdening pathology with high short-term mortality and severe long-term consequences. Its incidence, reaching as high as 10 cases per 1000 live births in the less developed countries, prompts the need for better awareness and prevention of cases at risk, together with management by easily applicable protocols. PA acts first and foremost on the nervous tissue, but also on the heart, by hypoxia and subsequent ischemia-reperfusion injury. Myocardial development at birth is still incomplete and cannot adequately respond to this aggression. Cardiac dysfunction, including low ventricular output, bradycardia, and pulmonary hypertension, complicates the already compromised circulatory status of the newborn with PA. Multiorgan and especially cardiovascular failure seem to play a crucial role in the secondary phase of hypoxic-ischemic encephalopathy (HIE) and its high mortality rate. Hypothermia is an acceptable solution for HIE, but there is a fragile equilibrium between therapeutic gain and cardiovascular instability. A profound understanding of the underlying mechanisms of the nervous and cardiovascular systems and a close collaboration between the bench and bedside specialists in these domains is compulsory. More resources need to be directed toward the prevention of PA and the consecutive decrease of cardiovascular dysfunction. Not much can be done in case of an unexpected acute event that produces $\mathrm{PA}$, where recognition and prompt delivery are the key factors for a positive clinical result. However, the situation is different for high-risk pregnancies or circumstances that make the fetus more vulnerable to asphyxia. Improving the outcome in these cases is possible through careful monitoring, identifying the high-risk pregnancies, and the implementation of novel prenatal strategies. Also, apart from adequately supporting the heart through the acute episode, there is a need for protocols for long-term cardiovascular follow-up. This will increase our recognition of any lasting myocardial damage and will enhance our perspective on the real impact of PA. The goal of this article is to review data on the cardiovascular consequences of PA, in the context of an immature cardiovascular system, discuss the potential contribution of cardiovascular impairment on short and long-term outcomes, and propose further directions of research in this field.

Keywords: perinatal asphyxia, neonatal risk, cardiovascular, ischemia-reperfusion, myocardial development, prenatal programming, hypothermia, therapeutic approaches 


\section{INTRODUCTION}

Asphyxia is characterized by hypoxia and hypercapnia that ensue due to lack of oxygen or ischemia. A limited degree of asphyxia is standard during childbirth (1). However, when prolonged or severe, fetal asphyxia may have harmful effects first and foremost on the fetal brain, but also other organs, like the heart, lungs, or the kidneys (2). Despite the efforts to reduce its incidence and consequences, perinatal asphyxia (PA) continues to occur globally in about 4 million babies every year (2) and accounts for $23 \%$ of all neonatal deaths and $8 \%$ of childhood deaths (3).

The incidence of PA depends on the definition used and the studied population. In developed countries, severe PA (defined by its consequences, death, or severe neurological impairment) is reported in 1 per 1,000 live births (4). In resource-poor countries, PA is more common and reflects the lack of access to adequate medical care. Reports from hospital-based studies in these settings suggest an incidence of 5-10 per 1,000 live births (5-7).

The main challenge for the clinician is the unpredictability of the phenomenon and the fact that once it starts, little can be done to minimize its harmful effects. Thus, it is easily understood why many preclinical and clinical studies have focused on finding early predictors for PA, as well as protective measures for both pre- and postpartum periods. The goal of the previously mentioned research is to generate standardized protocols that are readily available, especially in low-income areas, where PA is more prevalent.

Even if hypoxia leads to circulation redistribution to the brain, heart, kidney, and adrenal glands, a time-dependent injury still occurs in these organs. Although the majority of the studies have concentrated on the hypoxic brain injury, and how to diminish its impact, the effects on the cardiovascular system are equally important. Some studies report that $78 \%$ out of the total number of babies with severe PA suffered cardiac complications (2); in others, the value varies between 25 and $60 \%$ of cases $(8,9)$. The most extensive range is between 25 and $82 \%$ of the cases of neonatal asphyxia, comprising mild, moderate, and severe cardiac dysfunction (10-12).

Dysfunction of the cardiovascular system was repeatedly associated with a poor outcome in asphyxiated neonates $(10,13)$. Also, it seems probable that hypoxic-ischemic encephalopathy (HIE) is secondary to the multiorgan dysfunction, primarily to cardiorespiratory distress following PA, and not due only to poor oxygenation $(14,15)$. Hankins et al. (15) report that this was the case in $70 \%$ of babies in a clinical retrospective study. Thus, attention should be shifted away from the brain toward other organs that might consecutively impair the nervous system. New therapeutic targets could emerge by focusing on reestablishing normal circulation and counteracting the consequences of cardiovascular damage on HIE. Moreover, hypothermia, the primary therapeutic strategy currently in use for $\operatorname{HIE}(16,17)$, has minimal positive effects on the heart and other organs.

This article aims to review the current data on the developmental status of the cardiomyocyte and cardiovascular system at birth and how it withstands neonatal asphyxia, the primary protective and treatment strategies currently being tested and to formulate possible future directions for research in this area. An additional target is to assist in early identification of the neonates at risk for severe cardiovascular dysfunction since this is the primary category that might benefit from rapid and efficient intervention and setting up innovative therapeutic protocols.

\section{PERINATAL ASPHYXIA}

Parturition is accompanied by a transient period of asphyxia (hypoxia and hypercapnia) in the neonate as part of birth stress, during the shift from maternal-fetal umbilical respiratory gas exchange toward fetal lungs activation. This non-pathologic condition can turn into prolonged perinatal asphyxia (PA) in birth complications like prolonged labor or umbilical occlusion, with long-term consequences, mostly on the highly hypoxiasensitive immature brain (18).

Severe and prolonged asphyxia can result in either intrauterine fetal death and stillbirth or multiorgan failure in surviving neonates (2). Peripartum and intrapartum ischemic or hypoxic insults are, in many cases, impossible to anticipate and may be difficult to recognize before the delivery of the baby.

The most common neonatal signs of PA are described by the ACOG (American College of Obstetricians and Gynecologists) (19). They are presented in Figure 1, together with other clinical and biochemical measurements useful in the initial evaluation and further monitoring. These criteria only refer to those deliveries taking place at term or late preterm (gestational age $[G A] \geq 35$ weeks). They outline essential principles to establish a causal link between intrapartum hypoxic events and longterm neurological outcomes. For babies delivered before 3435 weeks' gestation, prematurity of their organs is likely to contribute to their long-term sequelae. The long-term postasphyxia consequences depend on multiple factors such as gestational age, duration, and severity of the insult, pre-existent fetal pathology, and postnatal care. Also, maternal infections (22), nocturnal light exposure (23), behavioral hazards (e.g., nicotine and alcohol) $(24,25)$, diabetes (26), high-fat diet (27), or nutritional deficiencies (28) promote a more severe outcome than the actual degree of asphyxia.

Since a severe PA is commonly accompanied by a critical neurologic outcome, with HIE and its long-term devastating sequelae, most of the basic and clinical research in the field of PA has been focused on the brain $(25,29)$. In postasphyxia HIE, brain lesions vary in severity, as classified by the Sarnat method (30) (stage 1-mild, stage 2-moderate, and stage 3-severe) which takes into account the baby's level of consciousness, neuromuscular and autonomic function, presence or absence of seizures and electroencephalographic recordings. This classification in stages of severity includes cardiovascular effects like irregularities of heart rate (HR) and blood pressure (BP), which are common during the period of reperfusion injury.

The mechanisms of post-asphyxia brain lesions imply the alteration of cerebral oxidative metabolism through a pathophysiological chain reaction, which ultimately leads to cellular death and brain damage. At the cellular level, brain 


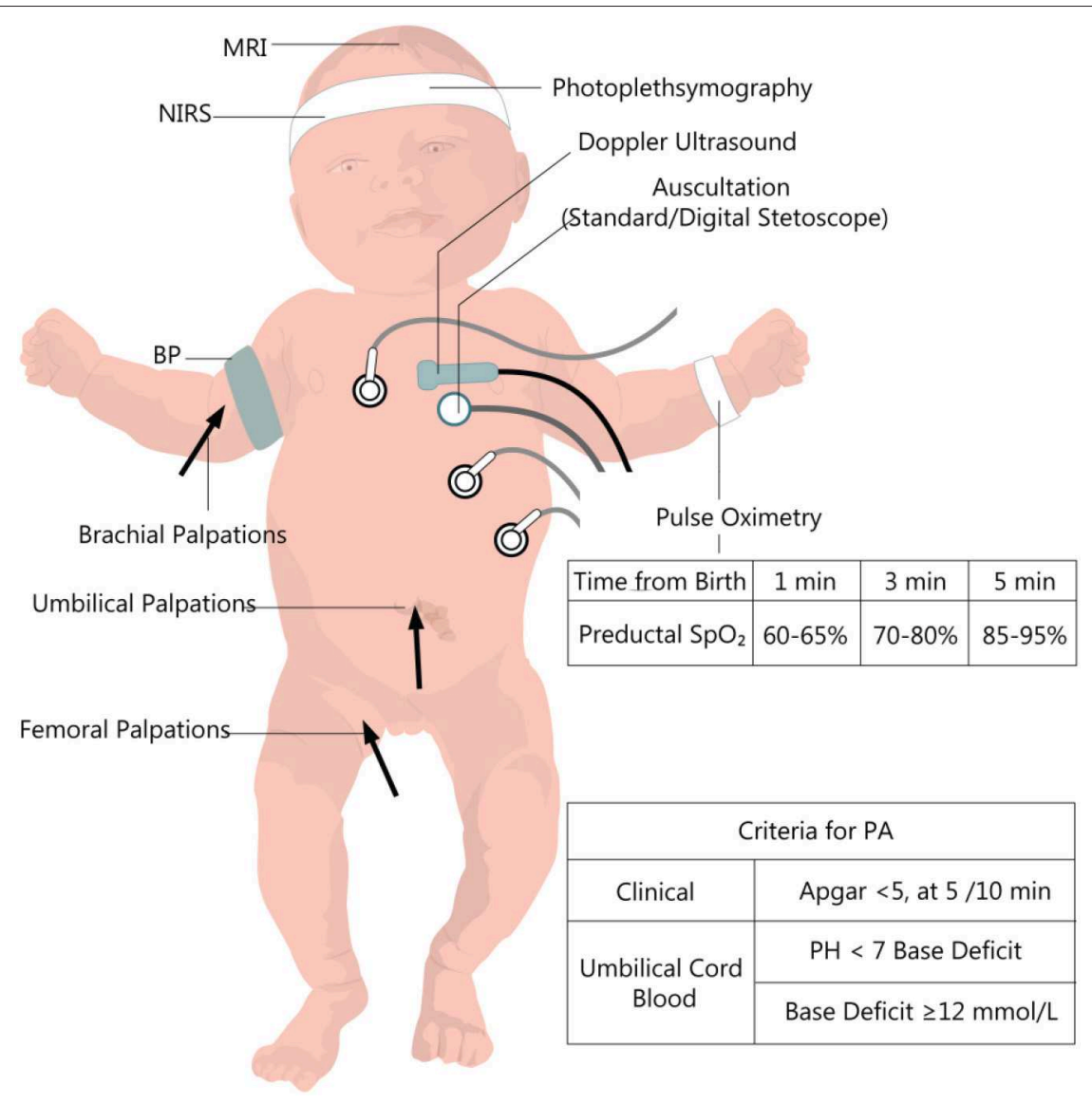

FIGURE 1 | Clinical and paraclinical evaluation of the newborn with perinatal asphyxia. PA, perinatal asphyxia, BP, Blood pressure; NIRS, near-infrared spectrophotometry. Data from the European and American guideline recommendations for time-dependent preductal $\mathrm{SpO}_{2}(20,21)$.

injury after PA develops in two phases. The first phase occurs during and immediately after the hypoxic-ischemic insult and is characterized by global hypoxia. When the baby is delivered and resuscitated, but also during the first few hours of life, there may be an apparent stabilization. However, there is a second phase of the injury, which begins $\sim 6 \mathrm{~h}$ after birth, characterized by post-hypoxic or post-ischemic hyperemia, with biochemical consequences such as excitotoxicity, oxidative stress, inflammation, and cytotoxicity (31).

However, there is still a lot to understand in the pathophysiological machinery underlying $\mathrm{PA}$ and to find an efficient treatment. The high level of unpredictability of PA makes the treatment strategies a real challenge. Finding novel solutions with regards to PA is a top priority for achieving the Millennium Development Goals set by the United Nations (7).

So far, the only available post-delivery option, along with gradual reoxygenation, remains exposing the child's brain to hypothermia to reduce the metabolic rate and the vascular permeability (32). Whole-body or head-only hypothermia started in the first $6 \mathrm{~h}$ after delivery, in selected neonates, reduces the neurological consequences of PA (33-35).

Hypothermia is thought to reduce oxidative stress, inflammation, and metabolic rate in the second phase of brain injury after PA. However, around $40 \%$ of neonates undergoing hypothermia still develop adverse neurologic outcomes. Many more that suffer PA are not eligible or do not have access to this therapy. For the treatment of brain hypoxic-ischemic encephalopathy, protocols of hypothermia (whole body or head only) are in place in almost all health care facilities in developed countries (36).

\section{CARDIOVASCULAR SYSTEM AND PERINATAL ASPHYXIA}

There is abundant data about the impact on the survival of cardiac dysfunction secondary to neonatal asphyxia $(10,37)$. Unfortunately, there are no follow up studies of long-term cardiovascular effects, neither for children with severe neonatal asphyxia with neurological sequelae nor for the ones with mild or moderate asphyxia episodes. The only cardiovascular pathology accompanying perinatal asphyxia with studies on long-term follow up is the persistent pulmonary hypertension of the newborn $(38,39)$.

In the following section, we will refer to the developmental features of the myocardium during the perinatal and postnatal 
period and pathophysiological, clinical, and molecular aspects of cardiovascular dysfunction in the acute setting of perinatal asphyxia.

\section{Normal Myocardial Development From Pre- to Postnatal Period}

There are significant structural and metabolic differences between the fetal and the adult cardiomyocyte (40). The maturation process starts at birth when the partial pressure of oxygen increases and profound changes in the pressure regimen in the pulmonary and systemic circulation occur (see Figure 2).

The need for greater contractile force initially drives hyperplasia, followed by hypertrophy of the cardiac cell mass. The metabolic switch from glycolytic to almost entirely oxidative metabolism reflects the conversion of the substrate from lactic acid to fatty acids, in a newly oxygen-enriched environment (40).

The structural and ultrastructural changes are driven by the need for higher efficiency in energy production and better communication between the cardiomyocytes, in correlation with the higher functional requirements. The location of gap junctions varies between fetal and adult cardiomyocytes (41, 42), with an adult-like arrangement toward the end of the first year of life. The specific distribution at birth suggests a less wellcoordinated syncytium than in the adult myocardium, hence its lower contractile force, especially under particular conditions (e.g., ischemia). This feature changes rapidly, as the connexins migrate toward the intercalated discs, transforming the cardiac cells in an efficient communicating mass.

Another important aspect is the vulnerability to the reactive oxygen species produced in the context of perinatal asphyxia and the ensuing ischemia/reperfusion lesion. Even if the antioxidant capacity accelerates during the last phase of gestation, at birth, it is still underdeveloped. There is a significant increase in superoxide dismutase (SOD) and catalase activity between the first and third months of extrauterine life. Also, there is a reduced capacity to react through the increased production of antioxidants (43).

\section{Physiopathology of the Cardiovascular Response to Perinatal Asphyxia}

The neonatal myocyte survives in hypoxic conditions because of its mainly glycolytic metabolism. But, hypoxic conditions delay the transition toward more proficient energy production, from anaerobic to aerobic. The lack of metabolic switch leads to reduced ATP production, which in turn makes the myocyte's contraction less efficient. The internal cellular organization, not fully developed at this stage, further contributes to suboptimal excitation-contraction coupling. Also, the basal contractile state is higher than in adults, which impedes both diastolic and systolic function (44). The overall effect is of a barely surviving, less functional myocardial cell (45).

Moreover, during reoxygenation, hyperoxia can occur, and generate reactive oxygen species. The cardiomyocyte is still vulnerable to this new aggression, and its defense mechanisms are not fully developed yet. The adverse effects can range from organelle dysfunction to programmed cell death produced during reoxygenation and reperfusion.

The main physiological adaptation of the cardiovascular system to hypoxia is the redistribution of blood flow vital organs, mainly heart and brain (46). However, this is insufficient in cases of severe asphyxia, as both brain and myocardium develop ischemic lesions. In all other territories, vasoconstriction

\begin{tabular}{|l|l|r|}
\hline \multicolumn{1}{|c|}{$\begin{array}{c}\text { Prenatal } \\
\text { Period }\end{array}$} & $\begin{array}{c}\text { Early Postnatal } \\
\text { Period }\end{array}$ \\
\hline Oxygenation $\left(\mathbf{P O}_{\mathbf{2}} \mathbf{)}\right.$ & & \\
\hline Oxygen Metabolism & & SOD, Catalase \\
\hline Antioxidant capacity & Glycolitic & Oxydative \\
\hline Metabolic Switch & Carbohydrates & Fatty acids \\
\hline Substrate Used & & Creatine kinase activity \\
\hline Energy Storage Capacity & & Hypertrophy \\
\hline Pressure Regimen & & \\
\hline Developmental Structural Changes & Hyperplasia \\
\hline
\end{tabular}

FIGURE 2 | Developmental changes from pre to postnatal periods. SOD, superoxide dismutase; ID, intercalated disk; PO2, partial pressure of oxygen. 
is translated into increased peripheral resistance. Hence, the moment of delivery is crucial, as, from a certain point, the high resistance in the fetal circulation short-circuits the blood to the low resistance placenta. The fetus remains with a small circulating blood volume. These facts may suggest the use of immediate clamping, but recent experimental data is contradictory (47). As Barberi et al. previously demonstrated, the newborn with severe asphyxia that correlates with signs of heart failure usually don't recover and die within the first week of life (10). This is another reason why efforts should be made to detect the severity of cardiac involvement as early as possible and focus on using all the available resources to stop or prevent further myocardial damage. Furthermore, apart from the low cardiac output that is due both to reduced contractile force and diminished preload, which is a consequence of pulmonary hypertension, neonatal asphyxia induces autonomic dysfunction, and vasoplegia (44).

The autonomic nervous system (ANS) is still incompletely developed at term. The sympathetic and parasympathetic evolve at different speeds during pregnancy, and this process continues for the following 6 months. Hence, it is essential to take the gestational age at birth into account when referring to autonomic dysfunction. Therefore, the more immature the autonomic system, the higher the disturbance in blood pressure and heart rate regulation will be.

Heart rate variability (HRV) is an excellent manner to investigate the well-being of the fetus, and it is also known to have prognostic significance (48). HRV is categorized as follows: (1) long term or low-frequency variability and (2) short term or high-frequency variability (49). Ultra-low frequency and verylow frequency HRV have been described, but they are underevaluated in the newborn (48). Thus, we will only refer to high or low frequency HRV.

The long term HRV is considered by some authors to result from a combination of sympathetic, parasympathetic, and baroreceptor influences (50). Others believe it to be the product of the baroreflex function (51). In the case of the short term variability, the parasympathetic activity is thought to be responsible (52).

There is still debate over the afferent branch of the parasympathetic response. It appears that chemoreceptors are the main drivers of the cardiovascular response. There is no change in heart rate or blood pressure in hypoxic states when the carotid and aortic body are experimentally absent $(53,54)$. Also, an important aspect is the function of the baroreceptors, as their dysfunction makes the HRV an undependable substitute for blood pressure monitoring (55).

Some studies found connections between HRV, survival, and neurological outcomes in the newborn with HIE $(56,57)$. HRV was tracked during and after therapeutic hypothermia, showing a positive correlation between low HRV and adverse effects after birth hypoxia (56). This recommends HRV as a useful tool to complement EEG or even identify babies that would benefit from more aggressive adjuvant therapies, besides hypothermia.

HIE and its severity are linked to increased parasympathetic tone and lower sympathetic tone, seen as decreased HRV in the severely ill (58).
To date, it is unclear whether the ANS dysfunction itself contributes to secondary brain lesions, or, the depressed HRV, as a marker of ANS dysfunction, is just a biomarker of evolving brain injury in the context of perinatal asphyxia and emerging HIE.

\section{Cardiovascular System - Clinical Repercussions of Perinatal Asphyxia}

Perinatal asphyxia triggers clinically relevant events within the cardiovascular system, ranging from heart rate, and systemic blood pressure variations to more profound changes, like myocardial dysfunction, myocardial ischemia, and pulmonary artery hypertension.

\section{Persistent Pulmonary Hypertension of the Newborn (PPHN)}

The transition from a high-resistance regime to low-resistance occurs in the pulmonary circulation in a very short time after birth. The adaptation is quite complex, involving the endothelium, a balance between mediators like endothelin 1, leukotrienes, and $\mathrm{NO}^{60}$. Hypoxia induces a disequilibrium in the ratio between endothelin and $\mathrm{NO}$, in the favor of the former, causing vasoconstriction through endothelial dysfunction and decreased NO production. Also, if hypoxia is persistent, upregulation of the NO synthase is blocked, and NO needed for pulmonary vasculature relaxation is lacking. This explains why treatment with inhaled NO is so efficient $(59,60)$. Later on, other added factors contribute to respiratory distress. These factors include left ventricular dysfunction, hypoxemia, oxygen administration, and even mechanical ventilation.

Persistent pulmonary hypertension of the newborn (PPHN) is associated with perinatal asphyxia. High vascular resistance is the effect of hypoxia on the pulmonary vasculature. Also, perinatal asphyxia is usually complicated by meconium aspirate and sepsis/pneumonia $(12,59,61,62)$. Most therapies to relieve pulmonary hypertension can have damaging effects on the cerebral circulation. Thus, special attention is needed in order not to do more harm than good. NO has proven a positive impact on the pulmonary circulation and the systemic arterial pressure (59). Venoarterial Extracorporeal Membrane Oxygenation (ECMO) is a lifesaving therapy in case of an oxygen index $>40$ in spite of optimal NO treatment and mechanical ventilation (38). The oxygenation index represents: $\left[\mathrm{FiO}_{2} / \mathrm{PaO}_{2}\right] \times \mathrm{PAW}$ where $\mathrm{FiO}_{2}$ is a fraction of inspired oxygen, $\mathrm{PaO}_{2}$ is the partial pressure of oxygen in arterial blood, and PAW is mean airway pressure. The survival rates for neonates on ECMO are over $80 \%$ but tend to decrease if the duration of this therapy lasts longer than seven days (63).

The recommendations for follow-up are similar to the ones for any pediatric pulmonary artery hypertension (39). PPHN is the only category of PA-related cardiovascular pathology that has the advantage of being included in follow-up protocols, thus being subject to consistent monitoring.

\section{Myocardial Ischemia}

As for any tissue, hypoxia leads to a mismatch between supply and demand, which results in decreased contractility (60). For adults, the protocol for recognizing hypoxic myocardial 
lesions is well-established. This is not the case for the newborn, where identifying ischemia is challenging. At birth, there is a lack of heterogeneity across the myocardial wall, concerning endocardial, midwall, and epicardial action potential (64). This may partly explain the repolarization aspect that resembles epicardial ischemia, with negative $\mathrm{T}$ waves. First attempts to identify cardiac injury in the neonatal setting analyzed only clinical signs and electrocardiography (ECG) tracings. In this manner, Martin-Ancel et al. identified $29 \%$ of patients with perinatal asphyxia to also have myocardial involvement (11). Barberi et al. stratified the severity of PA and observed the ECG patterns in these groups. The adverse outcomes correlate with the most severe ECG changes and also with the cardiac dysfunction documented through echocardiography (10) (see Figure 3). Troponin measurement is used in combination with $\mathrm{CK}$ and $\mathrm{CK}-\mathrm{MB}$ for detecting cardiac injury.

\section{Ventricular Dysfunction-Low Cardiac Output}

The change from in parallel operation in utero of the two ventricles to in series operation ex utero implies profound changes in both metabolism and structure of the fetal myocardium converting to adult myocardium (40, 65). Unfortunately, this whole reorganization and function optimization of the heart, if superimposed on the metabolic challenge of PA, renders it unprepared to react and adapt appropriately. This perinatal insult may cause acquired neonatal cardiomyopathy in an otherwise structurally normal heart. The cardiac performance is affected, but this situation is usually reversible. Since this pathology requires early recognition and treatment, close cardiac monitoring of severe cases of PA is necessary.

As echocardiography emerged as a valuable diagnostic tool for bedside evaluation in the adult patient, it also started being investigated for systematic use in the neonatal setting (see section Evaluation of cardiac injury post-asphyxia). Assessment of systolic and diastolic function, as well as structural changes (e.g., ventricular dilation), is suitable for recognizing cardiac dysfunction and guiding therapeutic interventions. Furthermore, modern echocardiographic techniques, usually reserved for adults, are now being tested to validate their use in this very delicate field (66).

\section{Arrhythmias}

The best-documented arrhythmia during PA is sinus bradycardia, with a cut-off value of 80 beats per minute $(14,67)$. Below this value, the evolution is unfavorable, sometimes leading to terminal bradycardia $(68,69)$. Moreover, bradycardia lasting more than 13 min correlates with the development of cerebral palsy (68). Also, bradycardia is a critical time marker for delivery, as more than $18 \mathrm{~min}$ from uterine rupture until delivery leads to substantial morbidity (70).

Bradycardia occurs immediately in severe cases of perinatal asphyxia. It is a result of acute hypoxia and consequent acidosis (71). Vagotomy and atropine administration experimental studies demonstrated that the vagus nerve is responsible for the pronounced bradycardia seen in neonatal asphyxia (72-74).

Interestingly, the response to asphyxia is different in utero and after birth. The heart rate abruptly decreases if the umbilical cord is occluded while the fetus is still in utero, but the heart rate only mildly drops if the occlusion happens after delivery (75).

\section{Hypotension}

Blood pressure is initially preserved due to the redistribution of blood through peripheral vasoconstriction. In cases with continued asphyxia, when the fetus is apneic, blood pressure drops. The severity and persistence of hypotension will translate into the length of inotropic support and extensive fluid replacement $(15,76)$.

On the other hand, hypotension is also a consequence of bradycardia, knowing that neonatal cardiac output is significantly dependent on heart rate. Hypotension can occur either in the phase of secondary apnea, as previously mentioned, or as a

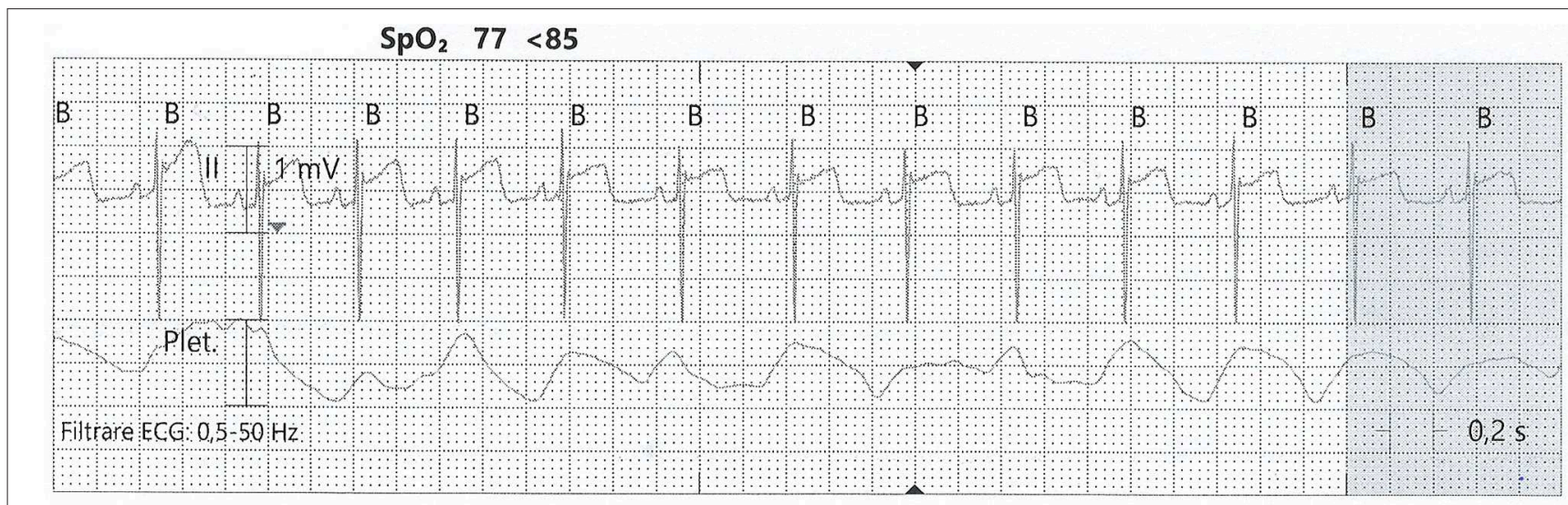

FIGURE 3 | ST-elevation on an ECG tracing from a neonate with PA. $\mathrm{SpO}_{2}$, partial pressure of oxygen; Plet, plethysmography (from the collection of Neonatology Department, Filantropia Clinical Hospital, Bucharest, Romania). 


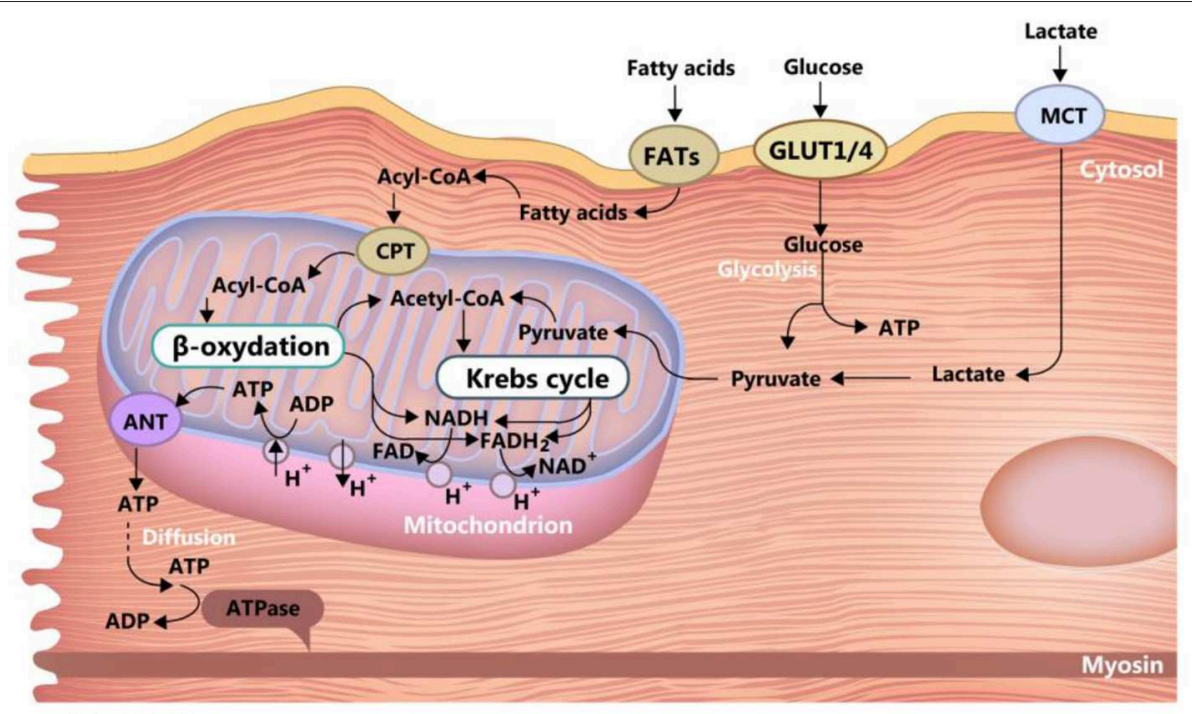

Normal

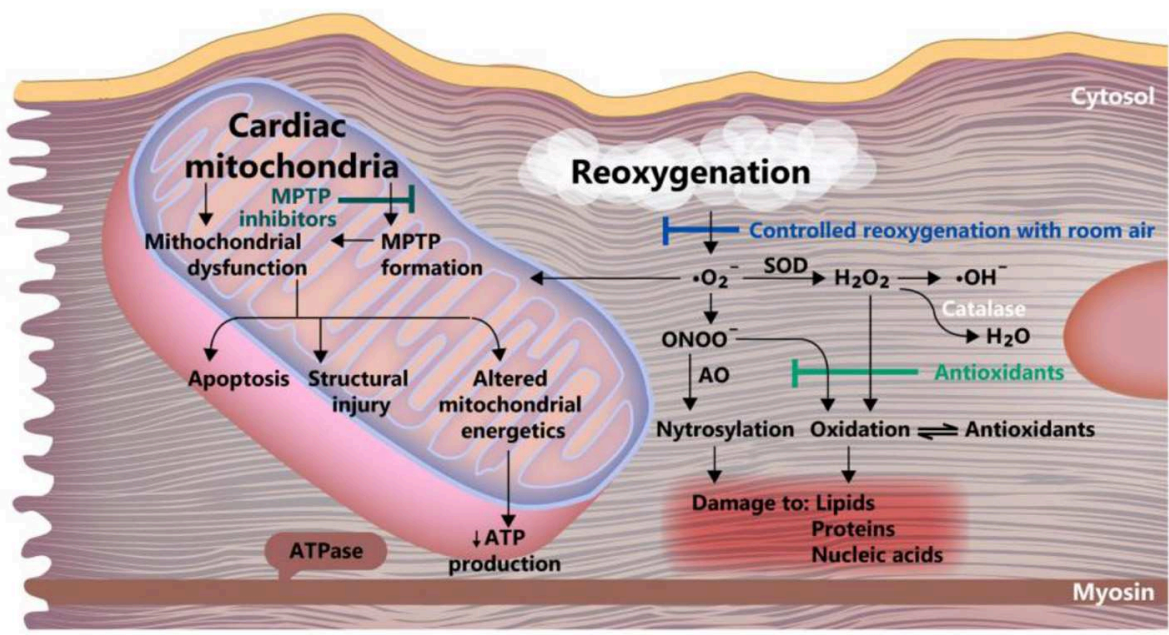

Asphyxia

FIGURE 4 | Differences between asphyxia and normoxia in the newborn myocardium cell. Acetyl-CoA, acetyl-coenzyme A; Acyl-CoA, acyl-coenzyme A; ANT, adenine nucleotide translocase; FAD and FADH ${ }_{2}$, oxidized and reduced, flavin adenine dinucleotide; FATs, fatty acid transporter; GLUT 1/4, glucose transporter 1 and 4; MCT, monocarboxylate transporter; MPTP, mitochondrial permeability transition pore; ONOO, peroxynitrite; ATP, adenosine triphosphate; ADP, adenosine diphosphate; NAD and NADH, oxidized and reduced nicotinamide adenine dinucleotide, SOD, superoxide dismutase.

side effect of therapeutic hypothermia $(67,77)$. Hypotension will gradually improve with the rewarming procedure (78).

\section{Perinatal Asphyxia Effect on the Neonatal Myocardium-Molecular Aspects}

The healthy neonate myocardial cell is still adapted to work under relatively hypoxic conditions (i.e., $20-25 \mathrm{mmHg}$ $\mathrm{PO}_{2}$ ), but with relatively low energy yield, using glycolytic pathways. This correlates with the fact that the heart does not need high performance until birth. In the case of perinatal asphyxia, this could prove to be beneficial, as the immature myocardial metabolism is adapted to low oxygen consumption, and fatty acid metabolism (adult) demands more oxygen than the glycolytic activity (40) (see Figure 4). Progressively, post-natal metabolism develops toward the adult cell organization and energy metabolism (see Figure 2). Thus, the neonatal cardiomyocyte is relatively resilient to ischemia, but as discussed below, less resistant to ischemia-reperfusion injury, mainly because of high vulnerability to the oxidative stress associated with reoxygenation.

The myocardial cell of the newborn is highly vulnerable to apoptosis (79), a feature that is further amplified by hypoxia through inhibition of adenosine triphosphate synthesis. The counteracting mechanisms in hypoxic-ischemic conditions are: 


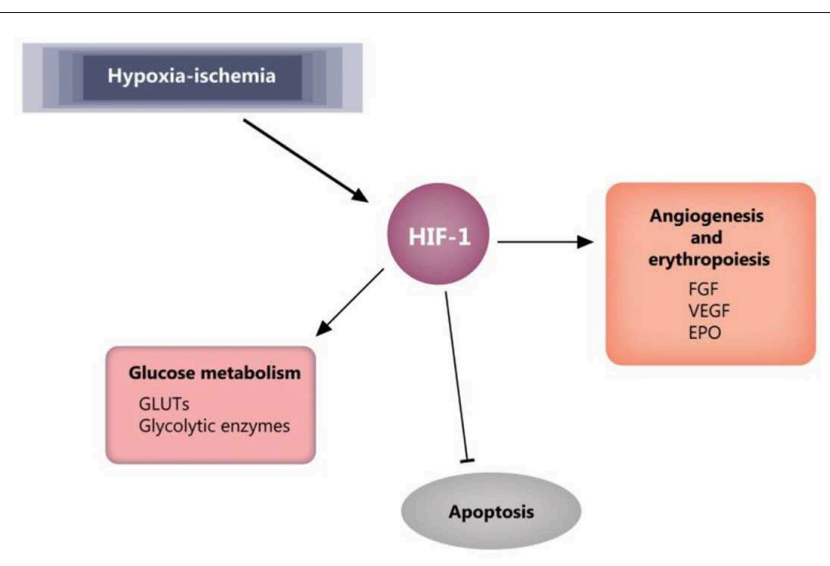

FIGURE 5 | HIF-1 effects in ischemia. Blunt arrow indicate inhibition, pointed arrows indicate stimulation. EPO, erythropoietin; FGF, fibroblast growth factor; GLUTs, glucose transporters; HIF-1, hypoxia-inducible factor 1; VEGF, vascular endothelial growth factor.

(1) Controlled reoxygenation, using room air, to carefully titrate the oxygen saturation, a mentioned before. (2) Use of antioxidants and (3) Inhibition of the mitochondrial permeability transition pore. These mechanisms are graphically summarized in Figure 4.

A key player in cellular response to hypoxia/ischemia is hypoxia-inducible factor $1-\alpha$ (HIF- $1 \alpha$ ), a transcriptional regulator of numerous genes involved in adaptive and survival mechanisms of cells transiting from normoxic to hypoxic conditions. Accumulation of HIF-1 $\alpha$ impact on cellular metabolism by increasing the anaerobic glycolysis and diminishing mitochondrial oxygen consumption (80). Also, HIF- $1 \alpha$ exerts protective effects by inducing vascular endothelial growth factor (VEGF) and erythropoietin (EPO) expression and supporting both angiogenesis and erythropoiesis (81). However, in the case of prolonged ischemia, HIF- $1 \alpha$ can also have deleterious effects, like apoptosis and stunting cell growth $(81,82)$. Moreover, dependent on the gestational age at birth, HIF- $1 \alpha$ was shown to have a role in signaling the mitochondrial transition toward an adult functioning pattern (83). The effects of HIF-1 are reviewed by Zhang et al. (81) and summarized in Figure 5.

Experimental studies have shown that cardiovascular phenotype can be modulated by environmental factors and preand perinatal events, like pre-eclampsia and perinatal hypoxia, through epigenetic transgenerational mechanisms (27, 84, 85). Epigenetic regulation of gene expression can result from DNA methylation/demethylation, histone modifications, and complementary binding of non-coding microRNAs (miRNA) to mRNA sequences. The fetal and neonate response to hypoxia is regulated by epigenetic mechanisms impacting on the synthesis and function of signaling molecules, receptors, ion channels, and enzymes, as recently reviewed by Ducsay et al. (80).

\section{Evaluation of Cardiac Injury Post-asphyxia}

The cardiac activity and its structural integrity can be closely monitored using varied methods that have a long history of testing and validation. These include electrocardiography and heart rate variability, echocardiography, along with a biochemical assessment of diagnostic and severity markers.

Electrocardiogram was one of the first investigations used to diagnose myocardial injury. Barberi et al. use three groups (normal, mildly ill, and severely ill) of newborn babies to describe four stages of ECG changes, from $\mathrm{T}$ wave changes to ST elevation/depression (see Figure 3). These correlated with the severity of myocardial damage and also with the general status at birth (10). Grade 4 ECG changes were present only in the severe asphyxia group, and all of these babies died in the first week of life. Also, the myocardial function assessed by echocardiography showed a marked decrease only in the severe asphyxia group. Thus, ECG is a valuable tool in identifying myocardial damage, but it needs to be used in combination with echocardiography and biochemical markers.

Heart rate variability (HRV) serves to carefully follow the cardiac activity, altogether with the autonomic influence. Its prognostic value is described and recognized, in general, and lately also in neonatal care (86). A recent study describes the normal HRV pattern in the healthy newborn, even in the first $6 \mathrm{~h}$, where the studies researching HIE are lacking information (48). Oliveira et al. describes in a recent review that all studies reporting HRV readings in HIE are consistent in predicting the neurological outcome of a baby suffering from PA (86). A decrease in HRV is associated with a poor outcome. For babies with PA, HRV analysis can assist in early risk stratification, and rush the decision for a particular therapeutic strategy, if performed promptly.

Echocardiography is a handy bedside tool for early diagnostic, functional cardiac evaluation, and monitoring. It is best performed as soon as there are signs of cardiovascular compromise. The neonatologist can assess the myocardial function, the presence of pulmonary hypertension, the persistence of shunting, and fluid repletion (10, 87-89). During therapeutic interventions, echocardiography can quickly depict changes in cardiac output, ventricular contractility or signs of pulmonary hypertension. Even more advanced techniques, like Tissue Doppler deformation indices of myocardial function, are currently used for neonate cardiac performance surveillance (90).

The biochemical markers are usually used in conjunction with clinical evaluation, ECG, and echocardiography. The most widely used are troponin $\mathrm{T}$ and $\mathrm{I}(77,91-93)$, creatine kinase (CK), creatine kinase $\mathrm{MB}(\mathrm{CK}-\mathrm{MB})(10,13,94)$, and the $\mathrm{N}$ terminal pro-brain natriuretic peptide (NT-proBNP) (95). There is a logical connection between low cardiac output, low coronary perfusion, and the release of troponin in the general circulation in asphyxiated infants (93). As in adult cardiology, there was an initial effervescence concerning troponin as a precise indicator of myocardial damage. Clinical experience shows that troponin tends to increase in many other clinical situations, as anemia, renal failure, tachyarrhythmia, or bradyarrhythmia. Still, it is the most widely used myocardial necrosis biomarker, as its dynamic is typical in myocardial infarction vs. other situations. $\mathrm{CK}$ and $\mathrm{CK}-\mathrm{MB}$ are used together with troponin to depict myocardial damage. CK-MB rise has also been linked to renal impairment as part of the multiorgan disfunction associated with PA. Therefore, renal implication should be ruled out before 


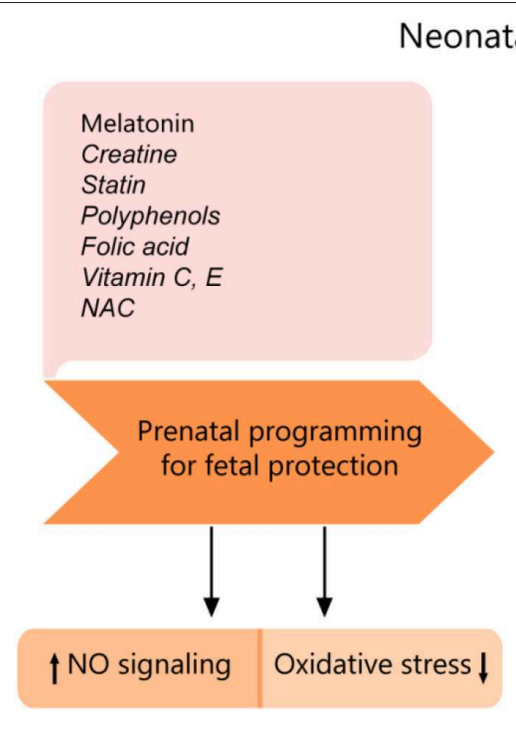

Neonatal Asphyxia

FIGURE 6 | Cardiomyocyte asphyxic injury timeline and potential therapeutic interventions. EPO, erythropoietin; IH, Intermittent ischemia; GIK, glucoseinsulin-potassium; NAC, N-Acetyl- cysteine; RIPc, remote ischemic pre/postconditioning; TH, therapeutic hypothermia. Experimental data are shown in italics.

confirming cardiomyocyte necrosis based only on CK-MB. NTproBNP is used as a marker of adult and neonatal cardiac failure in general, and also for babies with PA (96). Also, Copeptin seems to be emerging as a potential marker of myocardial damage $(95,97)$.

\section{The Cardiac Injury Accompanying Perinatal Asphyxia- From Prevention to Treatment}

Therapeutic strategies must be adapted to the timing of physiopathological events and particularities of the cellular metabolism, as each evolving phase has a specific treatment for optimum results (see Figure 6). The proper conduct should be correlated with the severity of asphyxia, given the fact that mild asphyxia does not have such a drastic effect on the cardiovascular system. Only a few strategies are being currently employed, namely therapeutic hypothermia, decreasing the oxidative stress by carefully titrating the oxygen saturation, stabilizing the mitochondrial membrane, and supplementing the endogenous antioxidant capacity (43). However, an increasing amount of experimental data suggests high translational potential and will be discussed in the following sections, correlated with their mechanism of action.

\section{Prenatal Programming}

Treatment can start even before birth, as prenatal programming in pregnancies at high risk for perinatal asphyxia shows real promise. A few pathologies associated with high risk are maternal hypertension, preeclampsia, history of placental abruption, macrosomia.

\section{Antioxidant therapy}

Exogenous antioxidant therapy has proven positive effects both in experimental and human studies (98). The potential therapeutic value resides in the ability of different substances to reduce oxidative stress in the scenario of PA, given the fact that the myocardium newborn has diminished antioxidant defenses.

Melatonin, the pineal hormone exhibiting a circadian secretion with maximum nocturnal values, seems to have the best protective results, with its capacity to scavenge free radicals, reduce oxidative stress, and improve cellular physiology (99). In concert with its scavenging activity, melatonin at physiological levels was shown to increase the mRNA expression and de novo synthesis of glutathione peroxidase and superoxide dismutase (100). An essential aspect during gestation is the fact that maternal circadian rhythm impacts on the programming of fetal and newborn circadian clocks (101). The pineal gland develops during the 6-8th week postnatally, and the maternal melatonin is the sole melatonin source for the fetus and neonate (102). In this context, nocturnal light exposure, known as functional pinealectomy, acts as a potent circadian rhythm disruptor suppressing the endogenous circulating melatonin levels (103). Consecutive melatonin deficiency and circadian system disturbances in the fetus have shown an impaired reaction to stressors and long-term metabolic and behavioral consequences in the adult offspring (23). However, in the case of maternal administration of melatonin during late gestation, there is a reduced capacity of the newborn lambs to react suitably and to adapt neonatal asphyxia (104), possibly by an increased NO availability. These experimental observations recommend further research to establish the required melatonin dose and timing of administration during gestation, in agreement with concomitant risk factors.

A more recent experimental study associates melatonin with $\mathrm{N}$-acetylcysteine, with positive results on antioxidant cardioprotection (105).

Other promising anti-oxidant substances in prenatal programming include folic acid, vitamin $\mathrm{C}$, vitamin $\mathrm{E}, \mathrm{N}$ acetylcysteine (NAC) (98), and polyphenols. One accessible 
dietary polyphenol with antioxidant properties is transresveratrol. When present in maternal diet, trans-resveratrol can diminish the PA-triggered inflammation and neuronal injury and increase the tolerance to asphyxia through transgenerational epigenetic mechanisms (85).

\section{Statins}

The effect of statins on endothelial progenitor cells (EPC) (106) mobilization, is relatively easy to study and implement, as there are ongoing studies for statin's effect on preeclampsia $(107,108)$. The downside is that the outcome will be difficult to evaluate, whether it will decrease the incidence of PA or increase the resilience to the hypoxic insult. To quantify these effects, large scale clinical studies are needed to observe the reduction in morbidity/mortality.

\section{Creatine}

Creatine is considered to be a worthy contender as a good source of energy in the context of PA. It can serve as energy supply not only for the brain but for the myocardium as well (2, 109). Multiple experimental studies using maternal diet supplementation with creatine show positive results, mainly on the diaphragm, but recent data indicate cardioprotective effects through HIF-1 activation (110).

\section{Ischemia-Reperfusion Therapeutic Window Reoxygenation with room air}

Precautions must be taken in order not to cause more damage in the process of reoxygenation, by increasing the oxidative stress, through high production of reactive oxygen species. In the asphyxic newborn, the danger of hyperoxia is as serious as for hypoxia (111). Trying to correct the low saturation of oxygen rapidly can expose the neonatal myocardium to an oxidative stress level that is greater than its handling capacity. Current guidelines suggest following the physiological curve of oxygen saturation rise, as observed in healthy newborn $(20,21,36)$.

\section{Therapeutic hypothermia and its cardiovascular effects}

The data about the impact of hypothermia on the cardiovascular system seems contradictory at first, with studies that confirm transitory adverse effects (14) and experimental data showing improved myocardial function after therapeutic cooling (8).

There was early controversy on hypothermia, as at first, it appeared to have a negative influence on the cardiovascular system. These adverse effects were sinus bradycardia, blood pressure decrease, and higher oxygen needs $(9,67)$. On the positive side, these effects were transient and subsided with the rewarming procedure.

These effects can be further categorized as affecting the heart rate or blood pressure (67). Regarding heart rate, there are accounts of arrhythmia, sinus bradycardia ( $<80$ beats/min), prolonged QT interval, arrhythmia requiring cessation of the procedure, or immediate medical intervention. Where blood pressure is concerned, hypotension (mean arterial pressure below $40 \mathrm{mmHg}$ ), or the need for inotropic treatment was detected. Therapeutic hypothermia causes hemodynamic instability in $33-77 \%$ of neonates (78). Also, another occurrence was persistent pulmonary hypertension requiring $\mathrm{NO}$ inhalation (67).

Later reports showed better outcomes on myocardial damage with the use of therapeutic hypothermia $(2,67,77)$. The myocardial injury was better assessed in these studies, both biochemically (CK-MB and troponin) and by echocardiography.

There are reports of a $67 \%$ reduction in cardiac output and a concordant decrease of heart rate and stroke volume during hypothermia, compared to the rewarming phase (112). A newer study found the opposite for stroke volume, in the context of decreased heart rate. They attributed the decrease in cardiac output during hypothermia to reduced metabolism, rather than a greater myocardial dysfunction (113). After rewarming, the myocardial function seems to be recovering faster than in noncooled asphyxiated infants (90). Some studies ascribed this increase to a rise in heart rate rather than an increase in contractile force per se $(76,114)$.

\section{Sustaining the circulation while the heart recovers}

Multiple studies showed the beneficial effect of classical methods of resuscitation, comprising of fluid repletion, use of inotropic drugs, $\mathrm{O}_{2}$ delivery, and cardiopulmonary resuscitation in case of cardiorespiratory arrest.

It was believed at first that the higher the oxygen concentration, the better the outcome (115). This position was reconsidered because of the target organ ischemia/reperfusion lesions caused by brutal reoxygenation, as discussed earlier in this review and especially for the myocardium. The Resair study, on 609 asphyxiated newborn, helped with this position change (116). By 2005, even though the general conduct was to use room air vs. $100 \%$ oxygen, a Cochrane meta-analysis on five studies that included 1,300 infants, did not find enough compelling data to warranty the use of room air therapy as guideline initial treatment without a backup oxygen source (117). Both European and American resuscitation guidelines recommend using the preductal $\mathrm{SpO}_{2}$ compared with normal $\mathrm{SpO}_{2}$ from healthy newborns and time passed from delivery (see Figure 1) $(36,118)$. Even healthy newborn might have a lower saturation $(<90 \%)$ for up to $14 \mathrm{~min}$ postpartum (111), so titration up to these values seems more adequate instead of a fixed $\mathrm{FiO}_{2}$ for the asphyxiated newborn. Also, there appears to be a need to individualize the treatment to avoid hyperoxia and at the same hypoxia in the more susceptible preterm male babies (119).

Apart from oxygenation, fluid resuscitation is another delicate subject, possibly causing cerebral edema if too aggressive (60). Unfortunately for the clinician, BP and perfusion are not always perfectly harmonized. Further evaluation, using modern techniques, has to be done to correlate blood pressure, cardiac output, and vascular resistance. Conventional parameters (plasma lactate, acid-base equilibrium, urine output) and newer methods [echocardiography and near-infrared spectroscopyNIRS (120, 121)] have an essential contribution in relaying the whole picture. The advantage of the latter is the ability to provide functional data on repletion status (122) or myocardial function and also a real-time estimation of the tissue perfusion and oxygenation (120). 
Accurately diagnosing the individual needs of the asphyxiated neonate will lead to the best decision in choosing the appropriate supportive therapy. The diagnosis concerns the myocardial function, the vasomotor function, and the pulmonary pressure. The ultimate purpose is to increase cardiac output and blood pressure and to decrease pulmonary pressure. The first line of treatment consisting of dopamine, dobutamine, epinephrine, and milrinone is completed by adjunctive therapy comprising norepinephrine, levosimendan, vasopressin, and hydrocortisone. This subject is extensively reviewed in a recent paper on supportive therapies of the asphyxiated newborn (44).

\section{Melatonin}

As previously mentioned, melatonin is extensively studied due to its potent antioxidant ability $(99,123)$. This capacity is of utmost interest in the context of perinatal asphyxia and the associated oxidative stress, as early postnatal treatment. Melatonin is neuroprotective in hypoxic-ischemic brain injury in vitro and in vivo animal models, and in asphyxiated term neonates when early administered post-asphyxia (124). Along with its antioxidant capacity, melatonin also elicits cardiovascular protection through anti-inflammatory, antilipidemic, and anti-hypertensive effects, which recommends it for clinical applicability (125).

Melatonin also acts as a protective molecule by favoring the parasympathetic system against the sympathetic one (126). This last effect is illustrated by a rise in plasma melatonin accompanying, as an adaptive mechanism, some cases of hypertension triggered by sympathetic overstimulation (127).

The cardiovascular effects of melatonin were recently described by Baltatu et al. in an elegant review of clinical and preclinical studies (128).

\section{Ischemic preconditioning/post-conditioning}

When perinatal asphyxia causes prolonged myocardial ischemia, the pattern of necrosis, apoptosis, infiltration with inflammatory cells, and scar formation can ensue. Histologic data confirming this come from experimental and necropsy studies (2). Ischemic preconditioning/postconditioning (129) emerged as a valuable method to use endogenous rescue mechanisms to decrease myocardial damage by ischemia/reperfusion injury $(130,131)$. Preconditioning has the advantage of having two phases, an early phase that occurs immediately and a late phase after $48-72 \mathrm{~h}$ after $(132,133)$. This biphasic pattern provides a longer window of protection. Even if these procedures are of practical use in severe neonatal asphyxia with a high risk of cardiovascular distress is still a question of debate. Intermittent hypoxia decreases the degree of apoptosis by reducing the endoplasmic reticulum stress $(134,135)$. There is some mechanistic similarity with remote ischemic preconditioning and also with pharmacological preconditioning (136). Remote preconditioning works for both brain (137) and myocardium $(138,139)$, but whether the same therapeutic window and dosages apply remains to be further documented. Furthermore, remote postconditioning seems to have positive results for both nervous tissue (140) and heart (94). The timely administration of these procedures could reduce the ischemia/reperfusion lesion in both the brain and myocardium, to reduce the morbidity/mortality of neonatal asphyxia.

\section{Magnesium}

Magnesium solutions are currently used intraoperatively because of its cardioprotective capacity during ischemia and reperfusion. This ability is linked to the blockage of L-type Calcium channels that produces a decrease of calcium loading, diminishing the myocardial energy demands (141) even in Langendorff-perfused hearts from young guinea pigs (142).

\section{Other therapeutic strategies}

Allopurinol and the noble gases such as argon (143) and xenon also show clinical promise but need further studies and confirmation, as some allopurinol results were contradictory to initial ones (144). Xenon is known as an ideal anesthetic agent with neuroprotective $(145,146)$ and cardioprotective properties (147). Its actions are mediated via KATP channels and other complex mechanisms converging toward antiapoptotic properties. In an international multicenter phase 3 study Hofland et al. proved that xenon anesthesia has cardioprotective effects on patients undergoing coronary bypass (148). Although xenon was used in neonates with brain injury and proved to be very safe but not superior to mild hypothermia (149), there are no studies to date that investigate xenon cardioprotective properties in neonates with cardiac failure following PA.

\section{Cell Death and Repair}

As the cardiac outcome is not the main target of research in neonates with perinatal asphyxia, studies into myocardial apoptosis and repair are lacking. We can only hope that experimental results will soon translate into practice.

\section{Reducing the apoptotic process}

Any mechanism reducing the apoptotic process is of particular interest in the context of myocardial ischemia/reperfusion injury. Selecting from the previously mentioned therapies, preconditioning, and melatonin appear to have the most convincing data. Intermittent hypoxia is beneficial, as it boosts the endogenous anti-apoptotic mechanisms (135). Melatonin inhibits apoptosis in mature cardiomyocytes (150), but also in H9C $_{2}$ cells (151), which are similar to neonatal myocardial cells. Melatonin also regulates HIF expression (152). HIF-1 modulation plays a crucial role in regulating the apoptotic process (153). Glucose -insulin-potassium (GIK) solution, similar to the one used for adults to metabolically activate the myocardium, has a positive influence on the apoptotic process as well (154). So far, it was successfully used in a rat neonatal myocardium ischemia/reperfusion model (155), but not in human neonates.

\section{Erythropoietin}

Although consistent results in small rodents indicated erythropoietin as useful in reducing the myocardial infarction area and promoting cardiac repair (156), human studies didn't confirm these effects. The issue seems to be the timing of erythropoietin administration (157) and also with the adverse events. 


\section{Stem Cells}

Stem cells research sprouted high hopes in regenerative medicine, with the perspective of progenitor cells replacing/improving the functionality of the ones damaged through hypoxic insult. Current data show the paracrine role of these cells and the stimulation of myocardial angiogenesis and repair (158). There are no follow-up protocols for cardiac dysfunction after perinatal asphyxia, apart from pulmonary hypertension; hence, stem cell protocols are hard to implement unless the cardiac dysfunction would be systematically sought after.

\section{Other potential strategies}

Topiramate, a sulfamate-substituted monosaccharide, a carbonic anhydrase inhibitor, similar to acetazolamide, was initially studied as an anticonvulsant and for neuronal repair and appeared to be useful in myocardial post-ischemia repair as well (159).

Carnosic acid, a phenolic diterpene with antioxidative properties, present in rosemary and common sage, was employed in ischemia-reperfusion injury and proved to be useful through the regulation of myocardial autophagy (160).

Oxytocin, a hypothalamic neuropeptide involved in maternalfetal interaction, with neuroprotective roles during birth (29), is also released from peripheric tissues, including heart and endothelial cells. Oxytocin was experimentally studied for its cardioprotective effect and is currently examined for its potential use in clinical trials, as recently reviewed by Wang et al. (161). In the immature neonate myocardium in rat, oxytocin translocates glucose transporter 4 (GLUT4) to the plasma membrane, regulating glucose uptake, thus sustaining cell metabolism and myocardial function during hypoxiaischemia. Oxytocin effects on GLUT4 were also found in human endothelial cells (162). Furthermore, oxytocin was shown to cooperate with atrial natriuretic peptide by acting as a natriuretic agent (163).

Sentinel proteins, such as poly(ADP-ribose) polymerase 1 (PARP-1), are activated in the context of oxidative stress to maintain genome integrity. Even if they have an initial beneficial effect, in the end, in the case of overproduction, they can cause cell death (164). Learning a lesson from the neuroprotective strategies, inhibition of sentinel proteins $(165,166)$ might be of assistance to the heart as well (167).

\section{DISCUSSION OF FUTURE DIRECTIONS}

After extensive research of the literature, we did not find longterm follow-up studies of the children that suffered a mild or moderate degree of PA and not even of those that survived a severe episode with neurological sequelae. The only type of follow up is set up for cases with persistent pulmonary hypertension. But, a recent long-term experimental study shows ultrastructure and contractility changes in adult rat myocardium (168). Thus, discovering if there is a link between the initial severity of PA, the neurodevelopmental outcome and the cardiovascular status in adulthood would be of particular interest. Therefore, periodical check-ups of the cardiac function in all children with PA comprising physical examination, echocardiography, and ECG Holter monitoring, would undoubtedly improve our perception of the real effect of PA on the cardiovascular system.

The best way to prevent prenatal asphyxia is to closely monitor the fetus in a way that would prompt rapid delivery in case of an acute event (169). Better prevention can also be attained by training obstetricians to expertly interpret cardiotocographies (CTGs) (170). Every case needs to be taken separately to prevent $\mathrm{PA}$ in babies that are not at risk for a pathological event at birth, but they manifest nonetheless as PA. For some of these cases, the pregnancy should have been considered at risk and thoroughly investigated, for example, in diabetic or hypertensive mothers.

Thus, antenatal screening of mothers with hypertension, preeclampsia, markers of preeclampsia (PlGF/sFLT), etc. is an excellent way to identify pregnancies that would benefit from antenatal treatment, given the risk of PA. As discussed in section creatine (109) is such a substance, with the advantage easy access and without significant adverse effects.

Also, gestational exposure to potential deleterious factors (macrosomia, IUGR, ethanol, nocturnal light exposure) induces a lower offspring tolerance to milder asphyxia. Therefore, a child that was supposed to have normal parameters at birth has the typical characteristics of PA. Special precautions need to be taken in preventing this outcome by closely monitoring the pregnancies at risk and possibly administering prenatal therapies (e.g., melatonin), or recommending epigenetic diets enriched in bioactive compounds (e.g., resveratrol).

In general, adult treatment of cardiac dysfunction can be applied in neonates, although some of the methods are not yet thoroughly tested. As an example, the GIK solution (glucoseinsulin-potassium) is used in treating cardiac dysfunction after cardiac surgery or myocardial infarction, with good long-term outcomes $(154,171,172)$. However, GIK solution hasn't been tested in neonate cardiac dysfunction induced by the PA. There is one experimental study performed in neonatal rats, investigating GIK solution effects on myocardium exposed to ischemiareperfusion injury that reduced the reactive oxygen species (155).

More studies need to focus on the diastolic function and explore whether there is a direct relationship between the severity of the acute brain damage and myocardial performance. Because of the pleiotropic cardiovascular manifestations induced by PA, hemodynamic monitoring guided by echocardiographic protocols could be a pivotal point in the management of PA.

As the myocardial function of the neonate is barely adapting to extrauterine conditions, the stress added by inotropic medications is not always the ideal therapeutic procedure. Cardiac dysfunction can be assisted by an extracorporeal device acting as an external blood pump, such as ECMO (extracorporeal membrane oxygenation). As a matter of fact, ECMO is used in neonates in specific conditions as congenital heart disease, myocarditis/cardiomyopathy, arrhythmias, and pulmonary hypertension (including PPHN associated with PA). As opposed to brain injury secondary to PA, cardiac failure per se due to PA is not a contraindication for ECMO in neonates. Furthermore, an ECMO-associated brain hemorrhagic event could compromise neurologic outcome $(173,174)$. Selected cases of neonates with PA, even without PPHN, could thus benefit from this type of circulatory support. 
The artificial womb, confirmed as beneficial for premature babies, is another possible solution for allowing the myocardium enough time to adapt to the extrauterine conditions (175). Whether this technique would also be of assistance in term neonates with severe PA, remains a question for further research.

\section{CONCLUSIONS}

Despite the recent progresses in perinatal care, the burden of neonatal asphyxia is still not reduced to match the Millennium Developmental Goal (176). The current treatments available rely on magnesium administration, vasopressor support, careful oxygen titration, and, only in well-equipped facilities, hypothermia. The real impact of cardiovascular dysfunction on long-term prognosis of PA survivors is not yet fully understood and evaluated.

Thus, individualized prevention of PA and its cardiovascular effects would be more beneficial than any treatment strategy. This ambitious goal could be achieved through an improved screening

\section{REFERENCES}

1. James LS, Weisbrot IM, Prince CE, Holaday DA, Apgar V. The acid-base status of human infants in relation to birth asphyxia and the onset of respiration. J Pediatr. (1958) 52:379-94. doi: 10.1016/S0022-3476(58)80058-X

2. LaRosa DA, Ellery SJ, Walker DW, Dickinson H. Understanding the full spectrum of organ injury following intrapartum asphyxia. Front Pediatr. (2017) 5:16. doi: 10.3389/fped.2017.00016

3. Bryce J, Boschi-Pinto C, Shibuya K, Black RE. WHO estimates of the causes of death in children. Lancet. (2005) 365:1147-52. doi: 10.1016/S0140-6736(05)71877-8

4. Endrich O, Rimle C, Zwahlen M, Triep K, Raio L, Nelle M. Asphyxia in the newborn: Evaluating the accuracy of ICD coding, clinical diagnosis and reimbursement: observational study at a swiss tertiary care center on routinely collected health data from 2012-2015. PLOS ONE. (2017) 12:e0170691. doi: 10.1371/journal.pone.0170691

5. Lawn JE, Cousens S, Zupan J. 4 Million neonatal deaths: when? where? why? Lancet. (2005) 365:891-900. doi: 10.1016/S0140-6736(05)71048-5

6. Lawn JE, Blencowe H, Oza S, You D, Lee AC, Waiswa P, et al. Every Newborn: progress, priorities, and potential beyond survival. Lancet. (2014) 384:189-205. doi: 10.1016/S0140-6736(14)60496-7

7. Lawn JE, Rajiv B, Bergstrom S, Bhutta ZA, Gary L, Ellis DM, ET AL. Setting research priorities to reduce almost one million deaths from birth asphyxia by 2015. PLoS Med. (2011) 8:e1000389. doi: 10.1371/journal.pmed.1000389

8. Rakesh K, Vishnu Bhat B, Adhisivam B, Ajith P. Effect of therapeutic hypothermia on myocardial dysfunction in term neonates with perinatal asphyxia - a randomized controlled trial. J Mater Fetal Neonatal Med. (2017) 31:2418-23. doi: 10.1080/14767058.2017.1344633

9. Ambalavanan N, Carlo WA, Kliegman RM, Geme JW, Stanton BF. BR Text Book of Pediatrics. London: Elsevier (2012). p. 569-73.

10. Barberi I, Calabrò MP, Cordaro S, Gitto E, Sottile A, Prudente $\mathrm{D}$, et al. Myocardial ischaemia in neonates with perinatal asphyxia Electrocardiographic, echocardiographic and enzymatic correlations. Eur J Pediatr. (1999) 158:742-47. doi: 10.1007/s004310051192

11. Martín-Ancel A, García-Alix A, Cabañas FGF, Burgueros M,Quero J. Multiple organ involvement in perinatal asphyxia. J Pediatr. (1995) 127:78693. doi: 10.1016/S0022-3476(95)70174-5

12. Tapia-Rombo JC, Carpio-Hernández AH, Salazar-Acuña E, AlvarezVázquez RM, Mendoza-Zanella V, Pérez-Olea CR-F. Detection of transitory myocardial ischemia secondary to perinatal asphyxia. Arch Med Res. (2000) 31:377-83. doi: 10.1016/S0188-4409(00)00088-6 system of high-risk pregnancies and close monitoring of fetal warning signs that prompt rapid delivery. Therefore, the moment of early intervention could be shifted even before birth, through prenatal programming, and watchful waiting for early predictive indicators of fetal distress.

\section{AUTHOR CONTRIBUTIONS}

MP and A-MZ contributed conception and design of this manuscript and wrote the first draft of the manuscript. AP, $\mathrm{BP}, \mathrm{GP}$, and LZ wrote sections of the manuscript. All authors contributed to manuscript revision, read, and approved the submitted version.

\section{FUNDING}

Open Access Publication of this paper is partially supported by Carol Davila University of Medicine and Pharmacy, Bucharest, Romania.
13. Singh V, Vohra R, Bansal M. Cardiovascular involvement in birth asphyxia. J Clin Neonatol. (2018) 7:20. doi: 10.4103/jcn.JCN_80_17

14. Thoresen M, Whitelaw A. Cardiovascular changes during mild therapeutic hypothermia and rewarming in infants with hypoxicischemic encephalopathy. Pediatrics. (2000) 106:92-9. doi: 10.1542/peds. 106.1.92

15. Hankins S, Koen AF, Gei SM, Lopez JW, Van H. Neonatal organ system injury in acute birth asphyxia sufficient to result in neonatal encephalopathy. Obstet Gynecol. (2002) 99:688-91. doi: 10.1016/S0029-7844(02)01959-2

16. Shah PS. Hypothermia: A systematic review and meta-analysis of clinical trials. Semin Fetal Neonatal Med. (2010) 15:238-46. doi: $10.1016 /$ j.siny.2010.02.003

17. Tagin MA, Woolcott CG, Vincer MJ, Whyte RK, Stinson DA. Hypothermia for neonatal hypoxic ischemic encephalopathy: an updated systematic review and meta-analysis. Arch Pediatr Adolescent Med. (2012) 166:558-66. doi: 10.1001/archpediatrics.2011.1772

18. E. Sipos A, Kerenyi B, Orsolits K, Demeter P, Bakos P, Pottyondi B, et al. A translational model of moderate perinatal asphyxia reveals lasting behavioral deficits in the absence of focal neuronal loss. J Cereb Blood Flow Metab. (2017) 37:470-1. doi: 10.1177/0271678X17695990

19. D'Alton ME, Hankins RL, Berkowitz J, Bienstock A, Ghidini J, Goldsmith R, et al. Nelson, Lu-Ann Papil KT. Executive summary: Neonatal encephalopathy and neurologic outcome, second edition Report of the American College of Obstetricians and Gynecologists' Task Force on Neonatal Encephalopathy. Obstet Gynecol vol. (2014) 123:896-901. doi: 10.1097/01.AOG.0000445580.65983.d2

20. Rüdiger D, Trevisanuto B, Urlesberger J, Wyllie J, Bruinenberg CCR. European resuscitation council guidelines for resuscitation 2015: Section 7. Resuscitation and support of transition of babies at birth. Resuscitation. (2015) 95:249-63. doi: 10.1016/j.resuscitation.2015.07.029

21. Panchal AR, Berg KM, Kudenchuk PJ, Del Rios M, Hirsch KG, Link MS, et al. American heart association focused update on advanced cardiovascular life support use of antiarrhythmic drugs during and immediately after cardiac arrest: an update to the american heart association guidelines for cardiopulmonary resuscitation and Em. Circulation. (2018) 138:e740-9. doi: 10.1161/CIR.0000000000000613

22. Neufeld MD, Frigon C, Graham AS, Mueller BA. Maternal infection and risk of cerebral palsy in term and preterm infants. J Perinatol. (2005) 25:108-13. doi: 10.1038/sj.jp.7211219

23. Voiculescu SE, Le Duc D, Roşca AE, Zeca V, Chiţtimuş DM, Arsene AL, et al. Behavioral and molecular effects of prenatal continuous light exposure in the adult rat. Brain Res. (2016) 1650:51-9. doi: 10.1016/j.brainres.2016.08.031 
24. Shinzawa M, Tanaka SH, Tokumasu D, Takada T, Tsukamoto M, Yanagita KK. Maternal smoking during pregnancy, household smoking after the child's birth, and childhood proteinuria at age 3 years. Clin J Am Soc Nephrol. (2017) 12:253-60. doi: 10.2215/CJN.05980616

25. Le Duc D, Spataru A, Ceanga M, Zagrean L, Schöneberg T, Toescu EC, et al. Developmental exposure to ethanol increases the neuronal vulnerability to oxygen-glucose deprivation in cerebellar granule cell cultures. Brain Res. (2015) 1614:1-13. doi: 10.1016/j.brainres.2015.04.009

26. Cnattingius S, Lindam A, Persson M. Risks of asphyxia-related neonatal complications in offspring of mothers with type 1 or type 2 diabetes: the impact of maternal overweight and obesity. Diabetologia. (2017) 60:1244-51. doi: $10.1007 /$ s00125-017-4279-2

27. Isac S, Panaitescu AM, Iesanu M, Grigoras IF, Totan A, Udriste A, et al. Maternal high-fat diet modifies the immature hippocampus vulnerability to perinatal asphyxia in rats. Neonatology. (2018) 114:355-361. doi: $10.1159 / 000491383$

28. Bamji MS, Muthy PVVS, Williams L, Vishnu M,Vardhana Rao MV. Maternal nutritional status and practies and perinatal, neonatal mortality in rural Andhra Pradesh, India. Indian J Med Res. (2008) 127:44-51.

29. Panaitescu AM, Isac S, Pavel B, Ilie AS, Ceanga M, Totan A, et al. Oxytocin reduces seizure burden and hippocampal injury in a rat model of perinatal Asphyxia. Acta Endocrinol. (2018) 14:315-9. doi: 10.4183/aeb.2018.315

30. Sarnat HB,Sarnat MS. Neonatal encephalopathy following fetal distress: a clinical and electroencephalographic study. Arch Neurol. (1976) 33:696-705. doi: 10.1001/archneur.1976.00500100030012

31. Millar LJ, Shi L, Hoerder-Suabedissen A, Molnár Z. Neonatal hypoxia ischaemia: mechanisms, models, and therapeutic challenges. Front. Cell. Neurosci. (2017) 11:78. doi: 10.3389/fncel.2017.00078

32. Shah PS, Ohlsson A, Perlman M. Hypothermia to treat neonatal hypoxic ischemic encephalopathy: Systematic review. Arch Pediatr Adolesc Med. (2007) 161:951-8. doi: 10.1001/archpedi.161.10.951

33. Aslam S, Strickland T, Molloy EJ. Neonatal encephalopathy: need for recognition of multiple etiologies for optimal management. Front. Pediatr. (2019) 7:142. doi: 10.3389/fped.2019.00142

34. Shankaran S, Pappas A, McDonald SA, Vohr BR, Hintz SR, Yolton K, et al. Childhood outcomes after hypothermia for neonatal encephalopathy. N Engl J Med. (2012) 366:2085-92. doi: 10.1056/NEJMoa1112066

35. Azzopardi D, Strohm B, Marlow N, Brocklehurst P, Deierl A, Eddama O, et al. Effects of hypothermia for perinatal asphyxia on childhood outcomes. $N$ Engl J Med. (2014) 371:140-9. doi: 10.1056/NEJMoa1315788

36. Jeffrey MP, Jonathan W, John K, Dianne LA, Leon C, Jay PG, et al. International consensus on cardiopulmonary resuscitation and emergency cardiovascular care science with treatment recommendations. Circulation. (2010) 46:401-16. doi: 10.1161/CIRCULATIONAHA.110.971127

37. Polglase GR, Centre TR, Ong T, Centre TR, Hillman NH. Cardiovascular alterations and multi organ dysfunction after birth asphyxia. Clin Perinatol. (2017) 43:469-83. doi: 10.1016/j.clp.2016.04.006

38. Puthiyachirakkal M, Mhanna MJ. Pathophysiology, management, and outcome of persistent pulmonary hypertension of the newborn: a clinical review. Front. Pediatr. (2013) 1:23. doi: 10.3389/fped.2013.00023

39. Rosenzweig EB, Abman SH, Adatia I, Beghetti M, Bonnet D, Haworth S, et al. Paediatric pulmonary arterial hypertension: updates on definition, classification, diagnostics and management. Eur Respir J. (2019) 53:1801916. doi: 10.1183/13993003.01916-2018

40. Piquereau J, Ventura-Clapier R. Maturation of cardiac energy metabolism during perinatal development. Front Physiol. (2018) 9:959. doi: 10.3389/fphys.2018.00959

41. Vreeker A, van Stuijvenberg L, Hund TJ, Mohler PJ, Nikkels PG, van Veen TA. Assembly of the cardiac intercalated disk during preand postnatal development of the human heart. PLoS ONE. (2014) 9:e94722. doi: 10.1371/journal.pone.0094722

42. Wang Q, Lin JL-C, Chan SY, Lin JJC. The Xin repeat-containing protein, $\operatorname{mXin} \beta$, initiates the maturation of the intercalated discs during postnatal heart development. Dev Biol. (2013) 374:264-80. doi: 10.1016/j.ydbio.2012.12.007

43. Gill RS, Pelletier JS, LaBossiere J, Bigam DL,Cheung PY. Therapeutic strategies to protect the immature newborn myocardium during resuscitation following asphyxia. Can J Physiol Pharmacol. (2012) 90:689-95. doi: 10.1139/y2012-041

44. Joynt C, Cheung PY. Cardiovascular supportive therapies for neonates with asphyxia - a literature review of pre-clinical and clinical studies. Front. Pediatr. (2018) 6:363. doi: 10.3389/fped.2018.00363

45. Vrancken SL, van Heijst AF, de Boode WP. Neonatal hemodynamics: from developmental physiology to comprehensive monitoring. Front Pediatr. (2018) 6:87. doi: 10.3389/fped.2018.00087

46. Jensen A, Garnier Y,Berger R. Dynamics of fetal circulatory responses to hypoxia and asphyxia. Eur J Obstetr Gynecol Reproduct Biol. (1999) 84:15572. doi: 10.1016/S0301-2115(98)00325-X

47. Polglase GR, Blank DA, Barton SK, Miller SL, Stojanovska V, Kluckow $\mathrm{M}$, et al. Physiologically based cord clamping stabilises cardiac output and reduces cerebrovascular injury in asphyxiated nearterm lambs. Arch Dis Child Fetal Neonatal Ed. (2018) 103:F530-8. doi: 10.1136/archdischild-2017-313657

48. Oliveira V, von Rosenberg W, Montaldo P, Adjei T, Mendoza J, Shivamurthappa V, et al. Early postnatal heart rate variability in healthy newborn infants. Front Physiol. (2019) 10:922. doi: 10.3389/fphys.2019. 00922

49. Fyfe KL, Yiallourou SR, Wong FY, Horne RSC. The development of cardiovascular and cerebral vascular control in preterm infants. Sleep Med Rev. (2014) 18:299-310. doi: 10.1016/j.smrv.2013.06.002

50. Campbell H, Govindan RB, Kota S, Al-Shargabi T, Metzler M, Andescavage $\mathrm{N}$, et al. Autonomic dysfunction in neonates with hypoxic ischemic encephalopathy undergoing therapeutic hypothermia impairs physiological responses to routine care events. J Pediatr. (2018) 196:38-44. doi: 10.1016/j.jpeds.2017.12.071

51. Rahman F, Pechnik S, Gross D, Sewell LT,Goldstein DS. Low frequency power of heart rate variability reflects baroreflex function, not cardiac sympathetic innervation. Clin Auton Res. (2011) 21:133-41. doi: 10.1007/s10286-010-0098-y

52. Vergales BD, Zanelli SA, Matsumoto JA, Goodkin HP, Lake DE, Moorman JR, Fairchild KD. Depressed heart rate variability is associated with abnormal EEG, MRI, and death in neonates with hypoxic ischemic encephalopathy. Am J Perinatol. (2013) 31:855-62. doi: 10.1055/s-0033-1361937

53. Stein P, White SE, Homan J, Hanson MA, Booking AD. Altered fetal cardiovascular responses to prolonged hypoxia after sinoaortic denervation. Am J Physiol. (1999) 276:R340-6. doi: 10.1152/ajpregu.1999.276.2.R340

54. Itskovitz J, Lagamma EF, Bristow J, Rudolph AM. Cardiovascular responses to hypoxemia in sinoaortic-denervated fetal sheep. Pediatr Res. (1991) 30:381-5. doi: 10.1203/00006450-199110000-00016

55. Govindan RB, Al-Shargabi T, Massaro AN, Metzler M, Andescavage NN, Joshi R, et al. Baroreflex dysfunction in sick newborns makes heart rate an unreliable surrogate for blood pressure changes. Pediatr Res. (2016) 79:929-33. doi: 10.1038/pr.2016.17

56. Massaro AN, Govindan RB, Al-Shargabi T, Andescavage NN, Metzler $\mathrm{M}$, Chang $\mathrm{T}$, et al. Heart rate variability in encephalopathic newborns during and after therapeutic hypothermia. J Perinatol. (2014) 34:836-41. doi: $10.1038 /$ jp. 2014.108

57. Goulding RM, Stevenson NJ, Murray DM, Livingstone V, Filan PM, Boylan GB. Heart rate variability in hypoxic ischemic encephalopathy: correlation with EEG grade and 2-y neurodevelopmental outcome. Pediatr Res. (2015) 77:681-7. doi: $10.1038 /$ pr.2015.28

58. Aliefendioglu D, Dogru T, Albayrak M, Misirlioglu ED, Sanli C. Heart rate variability in neonates with hypoxic ischemic encephalopathy. Indian J Pediatr. (2012) 79:1468-72. doi: 10.1007/s12098-012-0703-2

59. Lapointe A, Barrington KJ. Pulmonary hypertension and the asphyxiated newborn. J Pediatr. (2011) 158:e19-24. doi: 10.1016/j.jpeds.2010.11.008

60. Armstrong K, Franklin O, Sweetman D, Molloy EJ. Cardiovascular dysfunction in infants with neonatal encephalopathy. Arch Dis Child. (2012) 97:372-5. doi: 10.1136/adc.2011.214205

61. Yum SK, Seo YM, Kwun Y, Moon CJ, Youn YA, Sung IK. Therapeutic hypothermia in infants with hypoxic-ischemic encephalopathy and reversible persistent pulmonary hypertension: short-term hospital outcomes. J Matern Neonatal Med. (2018) 31:3108-14. doi: $10.1080 / 14767058.2017 .1365123$ 
62. Liu J, Feng ZC. Changes in pulmonary arterial pressure in terminfants with hypoxic-ischemic encephalopathy. Pediatr Int. (2009) 51:786-9. doi: 10.1111/j.1442-200X.2009.02854.x

63. Lazar DA, Cass DL, Olutoye OO, Welty SE, Fernandes CJ, Rycus PT, et al. The use of ECMO for persistent pulmonary hypertension of the newborn: a decade of experience. J Surg Res. (2012) 177:263-7. doi: 10.1016/j.jss.2012.07.058

64. Abd Allah ES, Aslanidi OV, Tellez JO, Yanni J, Billeter R, Zhang H, et al. Postnatal development of transmural gradients in expression of ion channels and $\mathrm{Ca}^{2+}$-handling proteins in the ventricle. J Mol Cell Cardiol. (2012) 53:145-55. doi: 10.1016/j.yjmcc.2012.04.004

65. Hew KW, Keller KA. Postnatal anatomical and functional development of the heart: a species comparison. Birth Defects Res B Dev Reprod Toxicol. (2003) 68:309-20. doi: 10.1002/bdrb.10034

66. Sehgal A, Wong F, Menahem S. Speckle tracking derived strain in infants with severe perinatal asphyxia: a comparative case control study. Cardiovasc Ultrasound. (2013) 11:34. doi: 10.1186/1476-7120-11-34

67. Jacobs SE, Berg M, Hunt R, Tarnow-Mordi WO, Inder TE, Davis PG. Cooling for newborns with hypoxic ischaemic encephalopathy. Cochrane database Syst Rev. (2013) 2013:CD003311 doi: 10.1002/14651858.CD003311.pub3

68. Kodama Y, Sameshima H, Yamashita R, Oohashi M, Ikenoue T. Intrapartum fetal heart rate patterns preceding terminal bradycardia in infants ( $>34$-weeks) with poor neurological outcome: a regional population-based study in Japan. J Obstet Gynaecol Res. (2015) 41:1738-43. doi: $10.1111 /$ jog.12797

69. Kodama Y, Sameshima H, Ikeda T, Ikenoue T. Intrapartum fetal heart rate patterns in infants ( $>$ or $=34$ weeks) with poor neurological outcome. Early Hum Dev. (2009) 85:235-8. doi: 10.1016/j.earlhumdev.2008. 10.007

70. Leung AS, Leung EK, Paul RH. Uterine rupture after previous cesarean delivery: maternal and fetal consequences. Am J Obstet Gynecol. (1993) 169:945-50. doi: 10.1016/0002-9378(93)90032-E

71. Zaichkin J, Weiner GM. Neonatal resuscitation program (NRP) 2011: new science, new strategies. Neonatal Netw. (2011) 30:5-13. doi: 10.1891/0730-0832.30.1.5

72. Thakor AS, Giussani DA. Effects of acute acidemia on the fetal cardiovascular defense to acute hypoxemia. Am J Physiol. (2009) 296:R90-9. doi: 10.1152/ajpregu.90689.2008

73. Reeves JT, Daoud FS, Eastin C. Effects of vagotomy on arterial pressure and blood gases in the fetal calf. Am J Physiol. (1971) 221:349-55. doi: 10.1152/ajplegacy.1971.221.1.349

74. Giussani DA, Spencer JA, Moore PJ, Bennet L, Hanson MA. Afferent and efferent components of the cardiovascular reflex responses to acute hypoxia in term fetal sheep. J Physiol. (1993) 461:431-49. doi: 10.1113/jphysiol.1993.sp019521

75. Sobotka KS, Morley C, Ong T, Polglase GR, Aridas JD, Miller SL, et al. Circulatory responses to asphyxia differ if the asphyxia occurs in utero or ex utero in near-term lambs. PLoS ONE. (2014) 9:e112264. doi: 10.1371/journal.pone.0112264

76. Wu TW, Tamrazi B, Soleymani S, Seri I, Noori S. Hemodynamic changes during rewarming phase of whole-body hypothermia therapy in neonates with hypoxic-ischemic encephalopathy. J Pediatr. (2018) 197:68-74.e2. doi: 10.1016/j.jpeds.2018.01.067

77. Liu X, Chakkarapani E, Stone J,Thoresen M. Effect of cardiac compressions and hypothermia treatment on cardiac troponin I in newborns with perinatal asphyxia. Resuscitation. (2013) 84:1562-7. doi: 10.1016/j.resuscitation.2013.07.003

78. Giesinger RE, Bailey LJ, Deshpande P, McNamara PJ. Hypoxic-ischemic encephalopathy and therapeutic hypothermia: the hemodynamic perspective. J Pediatr. (2017) 180:22-30.e2. doi: 10.1016/j.jpeds.2016. 09.009

79. Abdelwahid E, Pelliniemi LJ, Niinikoski H, Simell O, Tuominen J, Rahkonen $\mathrm{O}$, et al. Apoptosis in the pattern formation of the ventricular wall during mouse heart organogenesis. Anat Rec. (1999) 256:208-17. doi: 10.1002/(SICI)1097-0185(19991001)256:2<208::AID-AR12>3.0.CO;2-R

80. Ducsay CA, Goyal R, Pearce WJ, Wilson S, Hu XQ, Zhang L. Gestational hypoxia and developmental plasticity. Physiol Rev. (2018) 98 1241-334. doi: 10.1152 /physrev.00043.2017
81. Zhang Z, Yao L, Yang J, Wang Z, Du G. PI3K/Akt and HIF-1 signaling pathway in hypoxia-ischemia (Review). Mol Med Rep. (2018) 18:3547-54. doi: $10.3892 / \mathrm{mmr} .2018 .9375$

82. Hubbi ME, Semenza GL. Regulation of cell proliferation by hypoxia-inducible factors. Am J Physiol. (2015) 309:C775-82. doi: 10.1152/ajpcell.00279.2015

83. Menendez-Montes I, Escobar B, Palacios B, Gómez MJ, Izquierdo-Garcia JL, Flores L, et al. Myocardial VHL-HIF signaling controls an embryonic metabolic switch essential for cardiac maturation. Dev Cell. (2016) 39:72439. doi: 10.1016/j.devcel.2016.11.012

84. Meister TA, Rexhaj E, Rimoldi SF, Scherrer U, Sartori C. Effects of perinatal, late foetal, and early embryonic insults on the cardiovascular phenotype in experimental animal models and humans. Vasa - Eur J Vasc Med. (2016) 45:439-49. doi: 10.1024/0301-1526/a000573

85. Isac S, Panaitescu AM, Spataru A, Iesanu M, Totan A, Udriste A, et al. Trans-resveratrol enriched maternal diet protects the immature hippocampus from perinatal asphyxia in rats. Neurosci Lett. (2017) 653:30813. doi: 10.1016/j.neulet.2017.06.003

86. Oliveira V, Martins R, Liow N, Teiserskas J, von Rosenberg W, Adjei T, et al. Prognostic accuracy of heart rate variability analysis in neonatal encephalopathy: a systematic review. Neonatology. (2019) 115:89-93. doi: 10.1159/000493002

87. Aggarwal S, Natarajan G. Biventricular function on early echocardiograms in neonatal hypoxic-ischaemic encephalopathy. Acta Paediatr. (2017) 106:1085-90. doi: 10.1111/apa.13866

88. Aggarwal S, Agarwal P, Natarajan G. Echocardiographic prediction of severe pulmonary hypertension in neonates undergoing therapeutic hypothermia for hypoxic-ischemic encephalopathy. J Perinatol. (2019) 39:1656-62. doi: 10.1038/s41372-019-0442-6

89. Levy PT, Tissot C, Horsberg Eriksen B, Nestaas E, Rogerson S, McNamara PJ, et al. Application of neonatologist performed echocardiography in the assessment and management of neonatal heart failure unrelated to congenital heart disease. Pediatr Res. (2018) 84:78-88. doi: 10.1038/s41390-0180075-Z

90. Nestaas E, Skranes JH, Støylen A, Brunvand L, Fugelseth D. The myocardial function during and after whole-body therapeutic hypothermia for hypoxicischemic encephalopathy, a cohort study. Early Hum Dev. (2014) 90:247-52. doi: 10.1016/j.earlhumdev.2014.01.014

91. Pal P, Goel M. ECG changes in birth asphyxia and its correlation with Cardiac troponin - I. Int J Med Res Rev. (2015) 3:400-3.

92. Bader AK, Lanir A, Tamir EM. Cardiac troponin I serum concentrations in newborns: a study and review of the literature. Clin Chim Acta. (2006) 371:61-5. doi: 10.1016/j.cca.2006.02.018

93. Sehgal A, Wong F, Mehta S. Reduced cardiac output and its correlation with coronary blood flow and troponin in asphyxiated infants treated with therapeutic hypothermia. Eur J Pediatr. (2012) 171:1511-7. doi: 10.1007/s00431-012-1764-y

94. Zhong H, Gao Z, Chen M, Zhao J, Wang F, Li L, et al. Cardioprotective effect of remote ischemic postconditioning on children undergoing cardiac surgery: a randomized controlled trial. Paediatr Anaesth. (2013) 23:726-33. doi: 10.1111/pan.12181

95. Rouatbi H, Zigabe S, Gkiougki E, Vranken L, Van Linthout C, Seghaye MC. Biomarkers of neonatal stress assessment: a prospective study. Early Hum Dev. (2019) 137:104826. doi: 10.1016/j.earlhumdev.2019. 104826

96. Zhu R, Nie Z. A clinical study of the N-Terminal pro-brain natriuretic peptide in myocardial injury after neonatal asphyxia. Pediatr Neonatol. (2016) 57:133-9. doi: 10.1016/j.pedneo.2015.08.001

97. Evers KS, Wellmann S. Arginine vasopressin and copeptin in perinatology. Front. Pediatr. (2016) 4:75. doi: 10.3389/fped.2016. 00075

98. Brennan LJ, Goulopoulou S, Bourque SL. Prenatal therapeutics and programming of cardiovascular function. Pharmacol Res. (2019) 139:261-72. doi: 10.1016/j.phrs.2018.11.022

99. Yiallourou SR, Wallace EM, Miller SL, Horne RSC. Effects of intrauterine growth restriction on sleep and the cardiovascular system: the use of melatonin as a potential therapy? Sleep Med Rev. (2016) 26 64-73. doi: 10.1016/j.smrv.2015.04.001 
100. Mayo JC, Sainz RM, Antoli I, Herrera F, Martin V, Rodriguez C. Melatonin regulation of antioxidant enzyme gene expression. Cell Mol Life Sci. (2002) 59:1706-13. doi: 10.1007/PL00012498

101. Reiter RJ, Tan DX, Korkmaz A, Rosales-Corral SA. Melatonin and stable circadian rhythms optimize maternal, placental and fetal physiology. Hum Reprod Update. (2014) 20:293-307. doi: 10.1093/humupd/dmt054

102. Ferreira DS, Amaral FG, Mesquita CC, Barbosa AP, Lellis-Santos C, Turati AO, et al. Maternal melatonin programs the daily pattern of energy metabolism in adult offspring. PLoS ONE. (2012) 7:e38795. doi: 10.1371/journal.pone.0038795

103. Revell VL, Skene DJ. Light-induced melatonin suppression in humans with polychromatic and monochromatic light. Chronobiol Int. (2007) 24:1125-37. doi: 10.1080/07420520701800652

104. Thakor AS, Allison BJ, Niu Y, Botting KJ, Serón-Ferré M, Herrera EA, et al. Melatonin modulates the fetal cardiovascular defense response to acute hypoxia. J Pineal Res. (2015) 59:80-90. doi: 10.1111/jpi.12242

105. Ait Abderrahim L, Tä̈bi K, Abderrahim NA, Alomery AM, Abdellah F, Alhazmi AS, et al. Protective effects of melatonin and $\mathrm{N}$-acetyl cysteine against oxidative stress induced by microcystin-LR on cardiac muscle tissue. Toxicon. (2019) 169:38-44. doi: 10.1016/j.toxicon.2019.08.005

106. Elahi MM, Matata BM. Effects of maternal high-fat diet and statin treatment on bone marrow endothelial progenitor cells and cardiovascular risk factors in female mice offspring fed a similar diet. Nutrition. (2017) 35:6-13. doi: 10.1016/j.nut.2016.10.011

107. Zeisler H, Llurba E, Chantraine F, Vatish M, Staff AC, Sennström M, et al. Predictive value of the sFlt-1:PlGF ratio in women with suspected preeclampsia. N Engl J Med. (2016) 374:13-22. doi: 10.1056/NEJMoa1 414838

108. Hagmann H, Thadhani R, Benzing T, Karumanchi SA, Stepan $\mathrm{H}$. The promise of angiogenic markers for the early diagnosis and prediction of preeclampsia. Clin Chem. (2012) 58:837-45. doi: 10.1373/clinchem.2011.169094

109. Dickinson H, Ellery S, Ireland Z, LaRosa D, Snow R, Walker DW. Creatine supplementation during pregnancy: summary of experimental studies suggesting a treatment to improve fetal and neonatal morbidity and reduce mortality in high-risk human pregnancy. BMC Pregnancy Childbirth. (2014) 14:150. doi: 10.1186/1471-2393-14-150

110. Santacruz L, Arciniegas A, Darrabie M, Mantilla JG, Baron RM, Bowles DE, et al. Hypoxia decreases creatine uptake in cardiomyocytes, while creatine supplementation enhances HIF activation. Physiol Rep. (2017) 5:e13382. doi: 10.14814/phy2.13382

111. Oei JL,Vento M. Is there a "Right" amount of oxygen for preterm infant stabilization at birth? Front Pediatr. (2019) 7:354. doi: $10.3389 /$ fped.2019.00354

112. Gebauer CM, Knuepfer M, Robel-Tillig E, Pulzer F, Vogtmann C. Hemodynamics among neonates with hypoxic-ischemic encephalopathy during whole-body hypothermia and passive rewarming. Pediatrics. (2006) 117:843-50. doi: 10.1542/peds.2004-1587

113. Eriksen VR, Trautner S, Hahn GH, Greisen G. Lactate acidosis and cardiac output during initial therapeutic cooling in asphyxiated newborn infants. PLoS ONE. (2019) 14:e0213537. doi: 10.1371/journal.pone.02 13537

114. Sehgal A, Linduska N, Huynh C. Cardiac adaptation in asphyxiated infants treated with therapeutic hypothermia. J Neonatal Perinatal Med. (2019) 12:117-25. doi: 10.3233/NPM-1853

115. Klaus M, Meyer BP. Oxygen therapy for the newborn. Pediatr Clin North Am. (1966) 13:731-52. doi: 10.1016/S0031-3955(16)31880-6

116. Saugstad OD, Rootwelt T, Aalen O. Resuscitation of asphyxiated newborn infants with room air or oxygen: an international controlled trial: the Resair 2 study. Pediatrics. (1998) 102:e1. doi: 10.1542/peds.102.1.e1

117. Tan A, Schulze AA, O’Donnell CP, Davis PG. Air versus oxygen for resuscitation of infants at birth. Cochrane Database Syst Rev. (2005) 2005:CD002273. doi: 10.1002/14651858.CD002273.pub3

118. Wyckoff MH, Aziz K, Escobedo MB, Kapadia VS, Kattwinkel J, Perlman JM, et al. Part 13: neonatal resuscitation 2015 American Heart Association guidelines update for cardiopulmonary resuscitation and emergency cardiovascular care (Reprint). Pediatrics. (2015) 136:S196-218. doi: $10.1542 /$ peds.2015-3373G
119. Vento M, Cubells E, Escobar JJ, Escrig R, Aguar M, Brugada M, et al. Oxygen saturation after birth in preterm infants treated with continuous positive airway pressure and air: assessment of gender differences and comparison with a published nomogram. Arch Dis Child Fetal Neonatal Ed. (2013) 98:F423-5. doi: 10.1136/archdischild-2012-302369

120. Sood BG, McLaughlin K, Cortez J. Near-infrared spectroscopy: applications in neonates. Semin Fetal Neonatal Med. (2015) 20:164-72. doi: 10.1016/j.siny.2015.03.008

121. Garvey AA, Dempsey EM. Applications of near infrared spectroscopy in the neonate. Curr Opin Pediatr. (2018) 30:209-15. doi: 10.1097/MOP.0000000000000599

122. Evans N, Kluckow M. Superior vena cava flow in newborn infants: a novel marker of systemic blood flow. Arch Dis Child Fetal Neonatal Ed. (2000) 82:F182-7. doi: 10.1136/fn.82.3.F182

123. Nosjean JP, Nicolas F, Klupsch P, Delagrange E, Canet JAB. Comparative pharmacological studies of melatonin receptors: MT1, MT2 and MT3/QR2 tissue distribution of MT3/QR2. Biochem Pharmacol. (2001) 61:1369-79. doi: 10.1016/s0006-2952(01)00615-3

124. Aly H, Elmahdy H, El-Dib M, Rowisha M, Awny M, El-Gohary T, et al. Melatonin use for neuroprotection in perinatal asphyxia: A randomized controlled pilot study. J Perinatol. (2015) 35:186-91. doi: 10.1038/jp.2014.186

125. Dominguez-Rodriguez A. Melatonin in cardiovascular disease. Exp Opin Invest Drugs. (2012) 21:1593-6. doi: 10.1517/13543784.2012. 716037

126. Baker JKK. Role of melatonin in blood pressure regulation: an adjunct anti-hypertensive agent. Clin Exp Pharmacol Physiol. (2018) 45:755-66. doi: 10.1111/1440-1681.12942

127. Pechanova O, Paulis L, Simko F. Peripheral and central effects of melatonin on blood pressure regulation. Int J Mol Sci. (2014) 15:17920-37. doi: 10.3390/ijms151017920

128. Baltatu OC, Senar S, Campos LA, Cipolla-Neto J. Cardioprotective melatonin: translating from proof-of-concept studies to therapeutic use. Int J Mol Sci. (2019) 20:4342. doi: 10.3390/ijms20184342

129. Wang G, Zhang Y, Yang L, Chen Y, Fang Z, Zhou H, et al. Cardioprotective effect of remote ischemic preconditioning with postconditioning on donor hearts in patients undergoing heart transplantation: a single-center, double-blind, randomized controlled trial. BMC Anesthesiol. (2019) 19:48. doi: 10.1186/s12871-019-0720-z

130. Kumas M, Altintas O, Karatas E, Kocyigit A. Protective effect of ischemic preconditioning on myocardium against remote tissue injury following transient focal cerebral ischemia in diabetic rats. Arq Bras Cardiol. (2017) 109:516-26. doi: 10.5935/abc.20170164

131. Rosenberg JH, Werner JH, Moulton MJ, Agrawal DK. Current modalities and mechanisms underlying cardioprotection by ischemic conditioning. $J$ Cardiovascul Transl Res. (2018) 11:292-307. doi: 10.1007/s12265-018-9813-1

132. Das M, Das DK. Molecular mechanism of preconditioning. IUBMB Life. (2008) 60:199-203. doi: 10.1002/iub.31

133. Bolli R, Yellon DM, Dana A. This Review is Part of a Thematic Series on Preconditioning, Which Includes the Following Articles: Ischemic Preconditioning in Isolated Cells the Preconditioning Phenomenon: A Tool for the Scientist or a Clinical Reality? Late phase of ischemic preconditioning myocardial $\mathrm{K}$ ATP channels in preconditioning the preconditioning phenomenon a tool for the scientist or a clinical reality? (2000). Available online at: http://www.circresaha.org

134. Chen TI, Hsu YC, Lien CF, Lin JH, Chiu HW YK. Non-Lethal levels of oxidative stress in response to short-term intermittent hypoxia enhance Ca handling in neonatal rat cardiomyocytes. Cell Physiol Biochem. (2014) 33:513-27. doi: 10.1159/000358631

135. Chang JC, Hu WF, Lee WS, Lin JH, Ting PC, Chang HR, et al. Intermittent hypoxia induces autophagy to protect cardiomyocytes from endoplasmic reticulum stress and apoptosis. Front Physiol. (2019) 10:995. doi: 10.3389/fphys.2019.00995

136. Popescu M, Munteanu A, Isvoranu G, Suciu L, Pavel B, Marinescu B, et al. Dynamics of endothelial progenitor cells following sevoflurane preconditioning. Roum Arch Microbiol Immunol. (2011) 70:109-13.

137. Nyquist P, Georgakis MK. Remote ischemic preconditioning effects on brain vasculature. Neurology. (2019) 93:15-6. doi: 10.1212/WNL. 0000000000007724 
138. Gleadle JM, Mazzone A. Remote ischaemic preconditioning: closer to the mechanism. F1000Res. (2016) 5:2846. doi: 10.12688/f1000research.9633.1

139. Billah M, Ridiandries A, Allahwala U, Mudaliar H, Dona A, Hunyor S, et al. Circulating mediators of remote ischemic preconditioning: search for the missing link between non-lethal ischemia and cardioprotection. Oncotarget. (2019) 10:216-44. doi: 10.18632/oncotarget.26537

140. Zhou Y, Fathali N, Lekic T, Ostrowski RP, Chen C, Martin RD, et al. Remote limb ischemic postconditioning protects against neonatal hypoxic-ischemic brain injury in rat pups by the opioid receptor/akt pathway. Stroke. (2011) 42:439-44. doi: 10.1161/STROKEAHA.110.592162

141. Qi H, Soto-Gonzalez L, Krychtiuk KA, Ruhittel S, Kaun C, Speidl WS, et al. Does magnesium-supplemented cardioplegia reduce cardiac injury? A metaanalysis of randomized controlled trials. J Card Surg. (2015) 30:338-45. doi: $10.1111 /$ jocs. 12518

142. Imura H, Lin H, Griffiths EJ, Suleiman MS. Controlled hyperkalemic reperfusion with magnesium rescues ischemic juvenile hearts by reducing calcium loading. J Thorac Cardiovasc Surg. (2011) 141:1529-37. doi: 10.1016/j.jtcvs.2010.09.048

143. Qi H, Soto-Gonzalez L, Krychtiuk KA, Ruhittel S, Kaun C, Speidl WS, et al. Pretreatment with argon protects human cardiac myocyte-like progenitor cells from oxygen glucose deprivation-induced cell death by activation of AKT and differential regulation of mapkinases. Shock. (2018) 49:556-63. doi: 10.1097/SHK.0000000000000998

144. Kaandorp JJ, Benders MJ, Rademaker CM, Torrance HL, Oudijk MA, de Haan TR, et al. Antenatal allopurinol for reduction of birth asphyxia induced brain damage (ALLO-Trial); a randomized double blind placebo controlled multicenter study. BMC Pregnancy Childbirth. (2010) 10:30. doi: 10.1186/1471-2393-10-8

145. Bantel C, Maze M, Trapp S. Neuronal preconditioning by inhalational anesthetics: evidence for the role of plasmalemmal adenosine triphosphatesensitive potassium channels. Anesthesiology. (2009) 110:986-95. doi: 10.1097/ALN.0b013e31819dadc7

146. Ma D, Williamson P, Januszewski A, Nogaro MC, Hossain M, Ong LP, et al. Xenon mitigates isoflurane-induced neuronal apoptosis in the developing rodent brain. Anesthesiology. (2007) 106:746-53. doi: 10.1097/01.anes.0000264762.48920.80

147. Yellon DM, Rossello X. Xenon A Noble Member of the Cardioprotection Club*.

148. Hofland J, Ouattara A, Fellahi JL, Gruenewald M, Hazebroucq J, Ecoffey C, et al. Effect of xenon anesthesia compared to sevoflurane and total intravenous anesthesia for coronary artery bypass graft surgery on postoperative cardiac troponin release an international, multicenter, phase 3, single-blinded, randomized noninferiority trial. Anesthesiology. (2017) 127:918-33. doi: 10.1097/ALN.0000000000001873

149. Azzopardi D, Robertson NJ, Bainbridge A, Cady E, Charles-Edwards G, Deierl A, et al. Moderate hypothermia within $6 \mathrm{~h}$ of birth plus inhaled xenon versus moderate hypothermia alone after birth asphyxia (TOBY-Xe): a proofof-concept, open-label, randomised controlled trial. Lancet Neurol. (2016) 15:145-53. doi: 10.1016\%2FS1474-4422(15)00347-6

150. Zhou H, Ma Q, Zhu P, Ren J, Reiter RJ, Chen Y. Protective role of melatonin in cardiac ischemia-reperfusion injury: from pathogenesis to targeted therapy. J Pineal Res. (2018) 64:1-21. doi: 10.1111/jpi. 12471

151. Hu S, Zhu P, Zhou H, Zhang Y, Chen Y. Melatonin-induced protective effects on cardiomyocytes against reperfusion injury partly through modulation of IP3R and SERCA2a via activation of ERK1. Arq Bras Cardiol. (2018) 110:44-51. doi: 10.5935/abc. 20180008

152. Mauriz JL, Collado PS, Veneroso C, Reiter RJ, González-Gallego J. A review of the molecular aspects of melatonin's anti-inflammatory actions: Recent insights and new perspectives. J Pineal Res. (2013) 54:1-14. doi: 10.1111/j.1600-079X.2012.01014.x

153. Peng K, Chen WR, Xia F, Liu H, Meng XW, Zhang J, et al. Dexmedetomidine post-treatment attenuates cardiac ischaemia/reperfusion injury by inhibiting apoptosis through HIF-1 $\alpha$ signalling. J Cell Mol Med. (2019) 23:6797-804. doi: $10.1111 /$ jcmm. 14795

154. Li Y, Zhang L, Zhang L, Zhang H, Zhang N, Yang Z, et al. High-dose glucose-insulin-potassium has hemodynamic benefits and can improve cardiac remodeling in acute myocardial infarction treated with primary
Percutaneous coronary intervention: from a randomized controlled study. J Cardiovasc Dis Res. (2010) 1:104-9. doi: 10.4103/0975-3583.70899

155. Chun WJ, Nah DY, Bae JH, Chung JW, Lee H, Moon IS. Glucose-insulinpotassium solution protects ventricular myocytes of neonatal rat in an vitro coverslip ischemia/reperfusion model. Korean Circ J. (2015) 45:234-41. doi: $10.4070 / \mathrm{kcj} .2015 .45 .3 .234$

156. Talan MI, Latini R. Myocardial infarction: cardioprotection by erythropoietin. Methods Mol Biol. (2013) 965-302. doi: 10.1007/ 978-1-62703-308-4_17

157. Steppich B, Groha P, Ibrahim T, Schunkert H, Laugwitz KL, Hadamitzky M, et al. Effect of erythropoietin in patients with acute myocardial infarction: five-year results of the REVIVAL-3 trial. BMC Cardiovasc Disord. (2017) 17:38. doi: 10.1186/s12872-016-0464-3

158. Mount S, Kanda P, Parent S, Khan S, Michie C, Davila L, et al. Physiologic expansion of human heart-derived cells enhances therapeutic repair of injured myocardium. Stem Cell Res Ther. (2019) 10:316. doi: 10.1186/s13287-019-1418-3

159. Wang Z, Huang S, Sheng Y, Peng X, Liu H, Jin N, et al. Topiramate modulates post-infarction inflammation primarily by targeting monocytes or macrophages. Cardiovasc Res. (2017) 113:475-87. doi: 10.1093/cvr/cvx027

160. $\mathrm{Hu} \mathrm{M}$, Li T, Bo $\mathrm{Z}$, Xiang $\mathrm{F}$. The protective role of carnosic acid in ischemic/reperfusion injury through regulation of autophagy under T2DM. Exp Biol Med. (2019) 244:602-11. doi: 10.1177/1535370219840987

161. Wang P, Wang SC, Yang H, Lv C, Jia S, Liu X, et al. Therapeutic potential of oxytocin in atherosclerotic cardiovascular disease: mechanisms and signaling pathways. Front Neurosci. (2019) 13:454. doi: 10.3389/fnins.2019.00454

162. Florian M, Jankowski M, Gutkowska J. Oxytocin increases glucose uptake in neonatal rat cardiomyocytes. Endocrinology. (2010) 151:482-91. doi: 10.1210/en.2009-0624

163. Gimpl G, Fahrenholz F. The oxytocin receptor system: structure, function, and regulation. Physiol Rev. (2001) 81:629-83. doi: 10.1152/physrev.2001.81.2.629

164. Haile WB, Echeverry R, Wu F, Guzman J, An J, Wu J,Yepes M. Tumor necrosis factor-like weak inducer of apoptosis and fibroblast growth factor-inducible 14 mediate cerebral ischemia-induced poly(ADP-ribose) polymerase-1 activation and neuronal death. Neuroscience. (2010) 171:125664. doi: 10.1016/j.neuroscience.2010.10.029

165. Herrera-Marschitz M, Perez-Lobos R, Lespay-Rebolledo C, Tapia-Bustos A, Casanova-Ortiz E, Morales P, et al. Targeting sentinel proteins and extrasynaptic glutamate receptors: a therapeutic strategy for preventing the effects elicited by perinatal asphyxia? Neurotox Res. (2018) 33:461-73. doi: 10.1007/s12640-017-9795-9

166. Jagtap P, Szabó C. Poly(ADP-ribose) polymerase and the therapeutic effects of its inhibitors. Nat Rev Drug Discov. (2005) 4:421-40. doi: 10.1038/nrd1718

167. Pacher P, Szabó C. Role of poly(ADP-ribose) polymerase 1 (PARP-1) in cardiovascular diseases: the therapeutic potential of PARP inhibitors. Cardiovasc Drug Rev. (2007) 25:235-60. doi: 10.1111/j.1527-3466.2007.00018.x

168. Gurgul S, Buyukakilli B, Komur M, Okuyaz C, Balli E, Ozcan T. Does levetiracetam administration prevent cardiac damage in adulthood rats following neonatal hypoxia/ischemia-induced brain injury? Medicina. (2018) 54:12. doi: 10.3390/medicina54020012

169. Landman A, Immink-Duijker ST, Mulder E, Koster M, Xodo S, Visser $\mathrm{G}$, et al. Significant reduction in umbilical artery metabolic acidosis after implementation of intrapartum ST waveform analysis of the fetal electrocardiogram. Am J Obstet Gynecol. (2019) 221:63.e1-e13. doi: 10.1016/j.ajog.2019.02.049

170. Berglund S. "Every case of asphyxia can be used as a learning example." Conclusions from an analysis of substandard obstetrical care. J Perinat Med. (2012) 40:9-18. doi: 10.1515/JPM.2011.108

171. Svedjeholm R, Håkanson E, Vanhanen I. Rationale for metabolic support with amino acids and glucose-insulin-potassium (GIK) in cardiac surgery. Ann Thorac Surg. (1995) 59:S15-22. doi: 10.1016/0003-4975(94)00917-V

172. Schipke JD, Friebe R, Gams E. Forty years of glucose-insulin-potassium (GIK) in cardiac surgery: a review of randomized, controlled trials. Eur J Cardio-Thoracic Surg. (2006) 29:479-85. doi: 10.1016/j.ejcts.2006.01.023

173. Roeleveld PP, Mendonca M. Neonatal cardiac ECMO in 2019 and Beyond. Front Pediatr. (2019) 7:327. doi: 10.3389/fped.2019.00327 
174. Extracorporeal Life Support Organization. ECMO and ECLS > Registry > Overview. (2019). Available online at: https://www.elso.org/Registry/ Overview.aspx

175. Partridge EA, Davey MG, Hornick MA, McGovern PE, Mejaddam AY, Vrecenak JD, et al. An extra-uterine system to physiologically support the extreme premature lamb. Nat Publ Gr. (2017) 8:1-15. doi: 10.1038/ncomms15794

176. Liu L, Oza S, Hogan D, Chu Y, Perin J, Zhu J, et al. Global, regional, and national causes of under-5 mortality in 2000-15: an updated systematic analysis with implications for the Sustainable development goals. Lancet. (2016) 388:3027-35. doi: 10.1016/S0140-6736(16)31593-8
Conflict of Interest: The authors declare that the research was conducted in the absence of any commercial or financial relationships that could be construed as a potential conflict of interest.

Copyright (c) 2020 Popescu, Panaitescu, Pavel, Zagrean, Peltecu and Zagrean. This is an open-access article distributed under the terms of the Creative Commons Attribution License (CC BY). The use, distribution or reproduction in other forums is permitted, provided the original author(s) and the copyright owner(s) are credited and that the original publication in this journal is cited, in accordance with accepted academic practice. No use, distribution or reproduction is permitted which does not comply with these terms. 